\title{
THE USE OF MULTIVARIATE ANALYSIS TO LINK SEDIMENT CONTAMINATION AND TOXICITY DATA TO ESTABLISH SEDIMENT QUALITY GUIDELINES: AN EXAMPLE IN THE GULF OF CÁDIZ (SPAIN)
}

\section{EL USO DEL ANÁLISIS MULTIVARIANTE EN LA UNIÓN DE DATOS DE TOXICIDAD Y CONTAMINACIÓN PARA ESTABLECER GUÍAS DE CALIDAD DE SEDIMENTO: UN EJEMPLO EN LA BAHÍA DE CÁDIZ (ESPAÑA)}

\author{
T. Ángel DelValls ${ }^{1 *}$ \\ Jesús M. Forja ${ }^{1}$ \\ Abelardo Gómez-Parra ${ }^{2+}$ \\ ${ }^{1}$ Departamento de Química Física \\ Facultad de Ciencias del Mar, Universidad de Cádiz \\ Apartado 40 \\ 11510 Puerto Real, Cádiz, España \\ *E-mail: angel.valls@uca.es \\ ${ }^{2}$ Instituto de Ciencias Marinas de Andalucía, CSIC \\ Apartado oficial \\ 11510 Puerto Real, Cádiz, España
}

Recibido en mayo de 1997; aceptado en febrero de 1998

\begin{abstract}
To evaluate marine sediment quality in the Gulf of Cádiz, chemical concentration and toxicity test endpoints from sediments were linked using multivariate analysis. Sediment samples were collected synoptically at seven stations in two littoral ecosystems of the Gulf of Cádiz (five in the Bay of Cádiz and two in the salt marsh of the Barbate River), and subjected to six separate, replicated sediment toxicity tests and comprehensive sediment chemistry analyses. The toxic effects of sediments were tested using three operational sediment phases: whole sediment, using the estuarine amphipod Microdeutopus gryllotalpa (10 d static: survival) and the estuarine clam Ruditapes philippinarum (48 h static: reburial); sediment elutriates, using larvae of the estuarine bivalve Crassostrea angulata (48 h static: survival) and of the marine fish Sparus aurata (48 h static: survival); and interstitial waler, using populations of the estuarine rotifer Brachionus plicatilis (7 d static: population decline) and of the marine bacteria Photobacterium phosphoreum (Microtox ${ }^{3}$ ). To evaluate the levels of contamination, the concentrations in the sediments of organic carbon, 14 trace metals $(\mathrm{Fe}, \mathrm{Mn}, \mathrm{Cu}, \mathrm{Zn}$, $\mathrm{Pb}, \mathrm{Cd}, \mathrm{Ag}, \mathrm{Hg}, \mathrm{As}, \mathrm{Sn}, \mathrm{V}, \mathrm{Ni}, \mathrm{Co}$ and $\mathrm{Cr}$ ) and the surfactant linear alkylbenzenesulphonate (LAS) were measured. The results of the toxicity tests were compared in a dose-response relationship between sites, demonstrating a general agreement between the toxicity values determined by all the tests, except in the case of interstitial water toxicity (principally due to toxic mixtures of trace metals). Data derived from sediment chemistry and bioassays were assembled by multivariate statistical techniques (PCA and factor analysis), showing that the two data types could be represented by only five factors corresponding to five overlapping chemical-biological effect relations. Positive prevalence of

Present address: Departamento de Quimica Física, Facultad de Ciencias del Mar, Universidad de Cádiz, Apartado 40, 11510 Puerto Real, Cádiz, España.
\end{abstract}


these factors in the cases studied was used to establish those ranges in chemical concentrations associated with adverse effects. The sediment quality guidelines, in terms of concentrations at or below which biological effects have betil shown to be minimal ( $\mathrm{mg} \mathrm{kg}^{-1}$ dry sediment), are: $\mathrm{Hg}, 0.25$; $\mathrm{Ag}$, $0.78 ; \mathrm{Pb}, 66.80 ; \mathrm{Cr}, 101.2 ; \mathrm{LAS}, 2.6$.

Key words: ecotoxicology, sediment toxicity, sediment contamination, sediment quality guidelines, multivariate analyses.

\section{RESUMEN}

Para evaluar la calidad de los sedimentos marinos en el Golfo de Cádiz, los datos provenientes de concentraciones químicas y respuestas de toxicidad en sedimentos fueron unidos usando el análisis multivariante. Las muestras de sedimentos fueron recogidas sinópticamente en siete estaciones de dos ecosistemas litorales en el Golfo de Cádiz (cinco en la Bahía de Cádiz y dos en las marismas del río Barbate) y fueron sujetas a seis tests de toxicidad de forma independiente y replicada, así como a análisis químicos. Los efectos tóxicos en los sedimentos se chequearon utilizando tres fases operativas del sedimento: sedimento bruto, utilizando el anfípodo Microdeutopus gryllotalpa $(10 \mathrm{~d}$ estático: supervivencia) y la almeja de estuario Ruditapes philippinarum (48 h estático: enterramiento); extracto de sedimento, utilizando larvas del bivalvo de estuario Crassostrea angulata ( $48 \mathrm{~h}$ estático: supervivencia) y del pez marino Sparus aurata (48 h estático: supervivencia); y agua intersticial, utilizando poblaciones del rotifero de estuario Brachionus plicatilis $(7 \mathrm{~d}$ estático: decaimiento de la población) y de la bacteria marina Photobacterium phosphoreum (Microtox ${ }^{\circledR}$ ). Para evaluar los niveles de contaminación, se determinaron las concentraciones en los sedimentos de carbono orgánico, 14 metales traza ( $\mathrm{Fe}, \mathrm{Mn}, \mathrm{Cu}, \mathrm{Zn}, \mathrm{Pb}, \mathrm{Cd}, \mathrm{Ag}, \mathrm{Hg}, \mathrm{As}, \mathrm{Sn}, \mathrm{V}, \mathrm{Ni}$, Co y $\mathrm{Cr}$ ) y el detergente alquilbencenosulfonato lineal (LAS). Los resultados de los ensayos de toxicidad se compararon mediante relaciones de respuesta entre las diferentes estaciones, demostrando una concordancia general entre los valores de toxicidad determinados en todos los tests, excepto en el caso de la toxicidad en el agua intersticial (principalmente debido a mezclas de metales traza tóxicas). Los datos obtenidos en los ensayos químicos y de toxicidad se ensamblaron utilizando técnicas estadísticas multivariantes (análisis de factores), mostrando que los dos tipos de datos podrían ser representados por sólo cinco factores correspondientes a cinco relaciones que ensamblan relaciones entre los contaminantes y el efecto biológico. La contribución de estos factores en los casos estudiados fue utilizado para establecer aquellos intervalos en las concentraciones de contaminantes asociados con efectos adversos. Las guías de calidad de sedimentos, en términos de aquellas concentraciones a las cuales o por debajo de las cuales el efecto biológico se ha mostrado como mínimo, son ( $\mathrm{mg} \mathrm{kg}^{-1}$ de peso seco de sedimento): $\mathrm{Hg}, 0.25 ; \mathrm{Ag}, 0.78$; $\mathrm{Pb}, 66.80 ; \mathrm{Cr}, 101.2$; LAS, 2.6 .

Palabras clave: ecotoxicología, toxicidad de sedimentos, contaminación de sedimentos, guías de calidad de sedimentos, análisis multivariante.

\section{INTRODUCTION}

The assessment of polluted sediments is difficult due to the complex nature of the sediment matrix and the potential for exposure of aquatic organisms to in-place contaminants via several routes. Aquatic sediments are a major repository for persistent contaminants, the bioavailability of which cannot be determined by chemical analyses or field surveys alone. In this sense, sediment toxicity tests provide information on the toxicity of contaminated sediments

\section{INTRODUCCIÓN}

La valoración de los sedimentos polucionados es dificil debido a la naturaleza compleja de la matriz del sedimento y a la exposición de los organismos acuáticos a los contaminantes por diversas vías de exposición. Los sedimentos acuáticos son el mayor sumidero para los contaminantes persistentes, la biodisponibilidad de los cuales no puede ser determinada por análisis químicos o de campo por sí solos. En este sentido, los tests de toxicidad de sedimento ofrecen 
by measuring their effect on test organisms. Performing sediment toxicity tests using different routes of exposition (whole sediment, sediment elutriates and interstitial water) have been recommended as the correct way to evaluate the present-day toxicity as well as that potentially accumulated in those sediments tested (Chapman, 1988; Luoma and Ho, 1992). It is recognized that ecotoxicological testing needs to be based on standard test organisms and be supplemented by the use of some ambient bioassay. Furthermore, a battery of tests should be used in order to ensure that the "no effect level" in one test will also be discriminated at several trophic levels (Giesy and Hoke, 1989). In this paper we concentrate on the ecotoxicity associated with three different sediment phases: whole sediment, sediment elutriates and interstitial water in the Gulf of Cádiz, as determined by six acute toxicity tests. Amphipod survival, Mollusca larvae survival and Microtox ${ }^{\text {(B) }}$ sediment toxicity tests are widely used and adopted techniques, while the other three bioassays used here (clam reburial, fish larvae survival and rotifer decline population tests) are used as the ambient tests. From these different toxicity tests performed using sediments collected in situ, it is possible to establish criteria that can be used to assess sediment quality. Sediment quality guidelines are controversial and consensus is lacking as to whether such guidelines are necessary, whether they can be developed, and what is the best means of developing them. The present article combines sediment chemistry with sediment toxicity tests using multivariate analysis to derive quantitative guidelines for the chemical contaminants measured. Specific considerations in the interpretation of the multivariate analysis to the data included: (a) toxic chemicals affect biological responses more than natural physicochemical factors; (b) chemicals quantified for the analysis are those that are known to be responsible for biological effects, although co-varying chemicals not quantified may also have influence on the biological tests; and (c) although the chemicals probably act together as mixtures (i.e., synergistically) to influence the biological tests, their patterns in multivariate statistical analysis are estimated singly. información sobre la toxicidad de los sedimentos contaminados midiendo su efecto sobre ciertos organismos utilizados en el test. El desarrollo de tests de toxicidad utilizando diferente rutas de exposición (sedimento bruto, extractos de sedimentos y agua intersticial) ha sido recomendado como la manera correcta para evaluar la toxicidad actual, así como la potencialmente acumulada en los mencionados sedimentos (Chapman, 1988; Luoma y Ho, 1992). Es reconocido que las pruebas ecotoxicológicas necesitan estar basadas en ensayos estándares que son acompañados por ensayos noveles de tipo ambiental. Además, debería utilizarse una batería de tests para asegurar que el "nivel de no efecto" en uno de los tests será también discriminado al probar diferentes niveles tróficos (Giesy y Hoke, 1989). En este trabajo, nos hemos concentrado en la ecotoxicidad asociada con tres fases distintas del sedimento: sedimento bruto, extracto de sedimento y agua intersticial en el Golfo de Cádiz, mediante el uso de seis ensayos de toxicidad aguda. La supervivencia de anfípodos, larvas de molusco y el ensayo comercial Microtox ${ }^{(i)}$ son de amplia utilización y se consideran tests estándares, mientras que los otros tres bioensayos (enterramiento de almejas, supervivencia de larvas de pez y decaimiento de poblaciones de rotíferos) son usados como tests ambientales. A partir de estos tests de toxicidad distintos, desarrollados utilizando sedimentos recogidos in situ, es posible establecer criterios que pueden ser usados para valorar la calidad de los sedimentos. Las guías de calidad de sedimentos son controvertidas y adolecen de consenso en su necesidad, su desarrollo y cuál es la mejor manera de definirlas. El presente artículo combina análisis químicos y tests de toxicidad de sedimentos utilizando análisis multivariante para derivar guías cuantitativas de los contaminantes químicos medidos. En la interpretación de los datos obtenidos por la aplicación del análisis multivariante se incluyen las siguientes consideraciones específicas: (a) las respuestas biológicas se ven más afectadas por las sustancias tóxicas que por los factores fisicoquímicos naturales; (b) los contaminantes químicos cuantificados son aquellos conocidos que son responsables del efecto biológico, 
The objectives of this study were: (1) to establish the feasibility of using a battery of toxicity tests in different operative sediment phases (whole sediment, sediment elutriates and interstitial waters) to directly measure the global sediment toxicity; and (2) to use multivariate analysis (PCA and factor) to identify the ranges in which chemical concentrations are associated with adverse effects.

\section{MATERIALS AND METHODS}

\section{Characteristics of sediments and sample collection}

The stations selected for this study are located in two littoral ecosystems in the Gulf of Cádiz. The first one is the Bay of Cádiz (fig. 1) and the second one is the salt marsh of the Barbate River (fig. 2), both shallow-water ecosystems. In both areas, approximately half of the area $\left(20 \mathrm{~km}^{2}\right)$ has a water depth of less than $3 \mathrm{~m}$ and is almost stagnant. For these reasons, contamination of the water column is largely determined by the processes of chemical transfer across the water-sediment interface.

Composite sediment samples (10 to 11 grabs per sample) were collected at each of the seven stations, five from the Bay of Cádiz (CB1, CB2, CB3, CB4 and $\mathrm{CB} 5$ ) and two from the salt marsh of the Barbate River (BR1 and BR2). The sampling sites represent a range in contamination, from highly contaminated (i.e., $\mathrm{CB} 2$ and $\mathrm{CB} 5$ ) to relatively pristine (CB1 and $B R \#)$, with various sources of contamination and toxicity in sediments (Gómez-Parra et al., 1984; DelValls et al., in press). Clean sediment (CN) from Cádiz beach (fig. 1) and its extracted interstitial water were used as negative control references together with samples of oceanic waters. Dirty sediment (CP) collected from the discharge point of untreated sewage located in the town of San Fernando (fig. 1) and its extracted interstitial water were used as positive control (DelValls et al, 1996). The sediment samples were collected using a Van Veen grab. Only grabs that had achieved adequate penetration (2/3 of total volume) to collect the superficial $5 \mathrm{~cm}$ of the sediment and that showed no evidence of leakage or surface disturbance were aunque los contaminantes que varíen conjuntamente y los no cuantificados podrían tener también influencia en los tests biológicos; y (c) aunque los contaminantes actúan probablemente juntos como mezclas (i.e., sinergéticamente) en su influencia en los tests biológicos, sus tendencias en los análisis estadísticos multivariantes son estimadas de manera singular.

Los objetivos de este estudio fueron: (1) establecer la aplicabilidad del uso de una batería de tests de toxicidad en diferentes fases operativas del sedimento (sedimento bruto, extracto de sedimento y agua intersticial) para medir, global y directamente, la toxicidad del sedimento; y (2) usar el análisis multivariante (PCA y factor) para identificar los intervalos en los cuales las concentraciones de contaminantes están asociadas con efectos adversos.

\section{MATERIALES Y MÉTODOS}

\section{Toma de muestras y caracteristicas de los sedimentos}

Las estaciones seleccionadas en este estudio están localizadas en dos ecosistemas litorales del Golfo de Cádiz. El primero está en la Bahía de Cádiz (fig. 1) y el segundo en las marismas del río Barbate (fig. 2), siendo ambos ecosistemas someros. En ambas zonas, aproximadamente la mitad del área $\left(20 \mathrm{~km}^{2}\right)$ tiene una profundidad de agua de menos de $3 \mathrm{~m}$ y es casi estanca. Por estas razones, la contaminación de la columna de agua está determinada por procesos de transferencia de contaminantes a través de la interfase agua-sedimento.

En cada una de las siete estaciones, cinco en la Bahía de Cádiz (CB1, CB2, CB3, CB4 y CB5) y dos en las marismas del río Barbate (BR1 y BR2), se recogieron muestras de sedimentos (10 ó 11 dragas por muestra). Los lugares muestreados representan un intervalo en contaminación, desde altamente contaminados (CB2 y CB5) a relativamente limpios (CB1 y $B R \#)$, con varias fuentes de contaminación y toxicidad en sedimentos (Gómez-Parra et al., 1984; DelValls et al., en prensa). Como controles negativos de toxicidad se utilizaron: sedimento limpio $(\mathrm{CN})$ recolectado en la playa de 


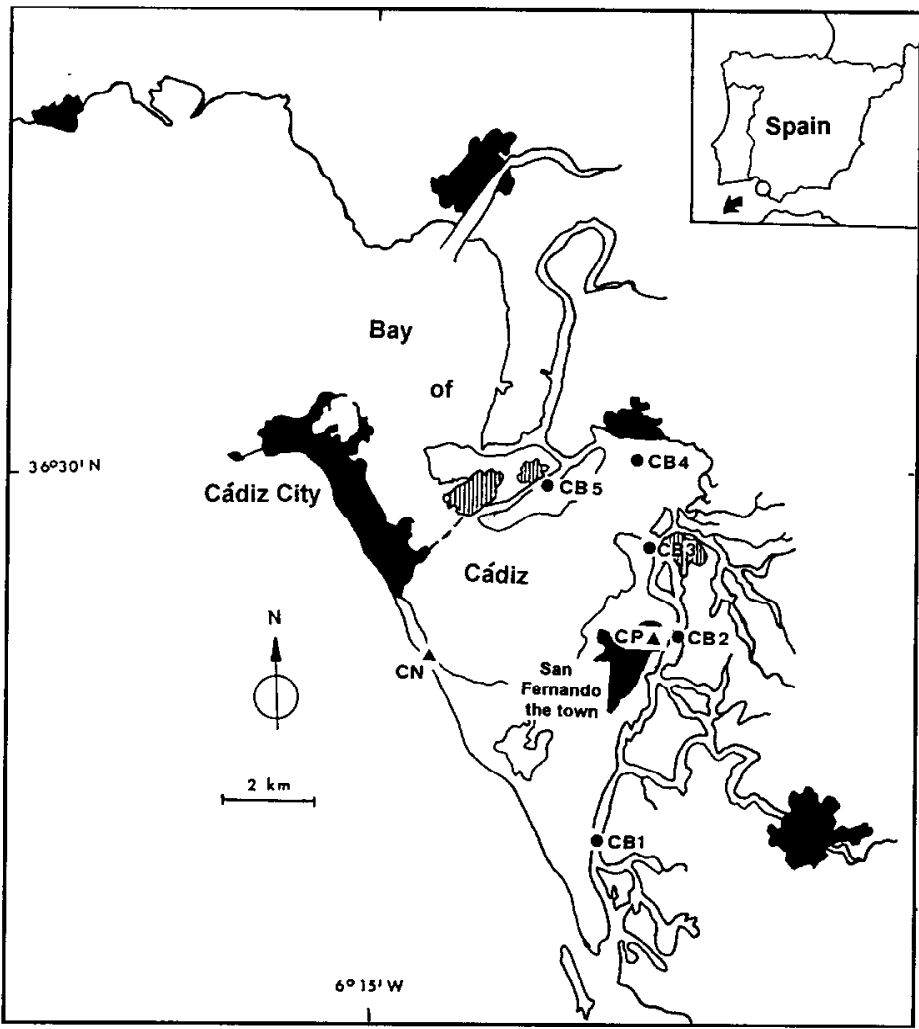

Figure 1. Map of the Bay of Cádiz showing the general areas sampled and locations of the sampling stations. Negative and positive controls ( $\mathrm{CN}$ and $\mathrm{CP}$, respectively) used in the toxicity tests are represented by triangles. Urban locations are represented by filled areas and industrial locations by areas with vertical lines.

Figura 1. Mapa de la Bahía de Cádiz, mostrando el área general de muestreo y la localización de las estaciones seleccionadas. I os controles de toxicidad, negativo y positivo (CN y $\mathrm{CP}$, respectivamente) usados en los tests de toxicidad están representados por triángulos. La localización de las zonas urbanas se representa por áreas obscuras y la localización de zonas industriales por áreas con líneas verticales.

retained for this study and transferred to a cooler. When sufficient sediment had been collected from a station (at least $20 \mathrm{~L}$ ), the contents of the cooler were homogenized with a Teflon spoon until no color or textural differences could be detected. Then, the coolers, chilled with ice, were transported to the laboratory. Samples were received at the laboratory 6-7 h after collection. The sediments were subsampled for chemical quantification (1.5-L aliquots) and toxicological characterization. After
Cádiz (fig. 1), su agua intersticial extraída y muestras de aguas oceánicas. Como controles positivos se utilizaron: sedimento sucio (CP) recogido en el punto de vertido del agua residual localizado en la ciudad de San Fernando (fig. 1) y su agua intersticial extraída (DelValls et al., 1996). Las muestras de sedimento fueron recogidas utilizando una draga Van Veen. Sólo aquellas dragas que mostraban una penetración adecuada ( $2 / 3$ del volumen total) para recoger los $5 \mathrm{~cm}$ superficiales del sedimento y que no 


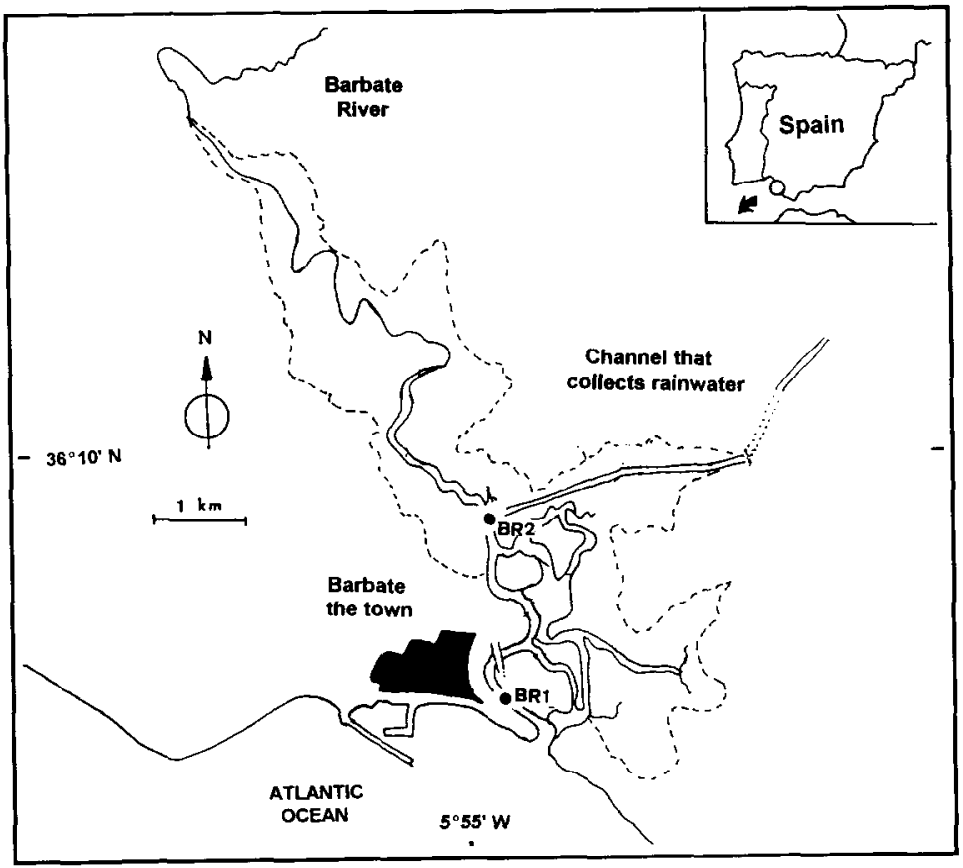

Figure 2. Map of the Barbate salt marsh, showing the general areas sampled and locations of the sampling stations.

Figura 2. Mapa de la marisma del río Barbate, mostrando el área general de muestreo y la localización de las estaciones seleccionadas.

that, sediment samples were maintained in the cooler at $4^{\circ} \mathrm{C}$ in the dark until their processing and analysis (toxicity testing was started the day after the final sample collection). Sediment was filtered $(0.5 \mathrm{~mm})$ prior to performance of the toxicity test. Prior to sample collection, all beakers used for the collection and storage of sediment samples were thoroughly cleaned using acid $10 \%\left(\mathrm{HNO}_{3}\right)$ and then rinsed in doubledistilled (Milli-Q) water before use. Oceanic water was collected $\left(36^{\circ} 21^{\prime} \mathrm{N}, 6^{\circ} 34^{\prime} \mathrm{W}\right)$ using Niskin bottles, placed on ice and transported to the laboratory, and then filtered $(0.45 \mu \mathrm{m})$.

\section{Chemical analyses}

For the study of sediment grain size and specific surface, an aliquot of wet sediment was analyzed using a laser particle sizer (Fritsch mostraban evidencias de pérdidas o deformaciones superficiales fueron las elegidas para este estudio y fueron transferidas a una nevera. Cuando se recogió suficiente sedimento de una estación (al menos $20 \mathrm{~L}$ ), el contenido de la nevera fue homogeneizado con una cuchara de teflón hasta que no se apreciaron diferencias de textura o de color. Después de esto, las neveras, con hielo, fueron transportadas al laboratorio. Las muestras se recibieron en el laboratorio 6-7 h después de la recolección. Los sedimentos fueron, entonces, submuestreados para la cuantificación química (alícuotas de 1.5 L) y para la caracterización toxicológica. Después de esto, las muestras de sedimento fueron mantenidas en las neveras a $4^{\circ} \mathrm{C}$ y en obscuridad hasta su procesamiento y análisis (los tests de toxicidad se comenzaron el día siguiente a la última recolección de muestra). El sedimento se filtró 
Analysette 22; DelValls et al., in press). The rest of the sediment was dried $\left(60^{\circ} \mathrm{C}\right)$ prior to chemical analyses. Dried sediments were gently homogenized. Organic carbon content was determined using the Gaudette et al. (1974) method, with the El Rayis (1985) modification. Elemental analysis was carried out with a Carlo Erba CHN analyzer (model 1106). The surfactant linear alkylbenzenesulphonate (LAS) was analyzed in a HP 1050 high-performance liquid chromatograph equipped with a fluorescence detector $\left(\lambda_{\mathrm{exc}}=225 \mathrm{~nm}\right.$ and $\left.\lambda_{\mathrm{em}}=295 \mathrm{~nm}\right)$, according to González-Mazo et al. (1997). For trace metal analysis, the sediments were digested as described by Loring and Rantala (1992). $\mathrm{Fe}, \mathrm{Mn}, \mathrm{Zn}$ and $\mathrm{Cu}$ concentrations in the extracts were determined by flame atomic absorption spectrophotometry with a PerkinElmer $2100 . \mathrm{Hg}$ and As concentrations were determined by means of a Perkin-Elmer MHS-FIAS coupled with a Perkin-Elmer, 4100 ZL spectrophotometer. The other trace metals were measured by graphite furnace atomic absorption spectrophotometry (Perkin-Elmer, $4100 \mathrm{ZL}$ ). Results are expressed as $\mathrm{mg} \mathrm{kg}^{-1}$ of dry sediment. The analytical procedure was checked using reference material (MESS-1 NRC and (RM 277 BCR).

\section{Toxicity tests}

Temperature, salinity and dissolved oxygen (Winkler method) were measured during toxicity testing for each bioassay.

\section{Sediment elutriate extraction}

An aliquot of approximately $3 \mathrm{~L}$ of sample was obtained $24 \mathrm{~h}$ after the last collection of sediments. Sediment aliquots $(3 \mathrm{~L})$ for each station, collected from the nine sites (seven stations and the negative and positive sediment controls), were transferred to $10-\mathrm{L}$ glass vessels and diluted with clean seawater in a $1: 2 \mathrm{v} / \mathrm{v}$ proportion and maintained during $48 \mathrm{~h}$ in agitation, followed by a settling-down process during $24 \mathrm{~h}$. After this, the supernatant was carefully decanted and prepared to be used in each elutriate toxicity test.
$(0.5 \mathrm{~mm})$ antes de comenzar los tests de toxicidad. Antes de la toma de muestra, todos los contenedores utilizados en la recolección y el almacenaje de las muestras de sedimento fueron concienzudamente limpiados utilizando $\mathrm{HNO}_{3}$ $(10 \%)$ y entonces enjuagados por duplicado en agua doblemente destilada (Milli-Q). El agua oceánica fue muestreada $\left(36^{\circ} 21^{\prime} \mathrm{N}, 6^{\circ} 34^{\prime} \mathrm{O}\right)$ utilizando botellas Niskin, colocada en hielo $y$ transportada al laboratorio, donde fue filtrada $(0.45 \mu \mathrm{m})$.

\section{Análisis químicos}

Para el estudio del tamaño de grano y la superficie específica del sedimento, se tomó un alícuota de sedimento húmedo que fue analizado utilizando un contador de partículas por láser (Fritsch Analysette 22; DelValls et al, en prensa). El resto del sedimento se secó $\left(60^{\circ} \mathrm{C}\right)$ antes del análisis. Los sedimentos secos fueron suavemente homogeneizados. El contenido de carbono orgánico fue determinado usando el método de Gaudette et al. (1974), con la modificación de El Rayis (1985). El análisis elemental fue realizado con un analizador de CHN Carlo Erba (modelo 1106). El tensioactivo alquilbencenosulfonato lineal (LAS) fue analizado en un cromatógrafo líquido de alta resolución HP 1050 con un detector de fluorescencia $\left(\lambda_{\text {exc }}=225 \mathrm{~nm} \mathrm{y} \lambda_{\text {em }}=295 \mathrm{~nm}\right)$, según el método de González-Mazo et al. (1997). Para el análisis de los metales traza, los sedimentos se digirieron según describen Loring y Rantala (1992). Las concentraciones de $\mathrm{Fe}, \mathrm{Mn}, \mathrm{Zn}$ y $\mathrm{Cu}$ en los extractos se determinaron por espectrofotometría de absorción atómica de llama con un Perkin-Elmer 2100. Las concentraciones de $\mathrm{Hg}$ y As se determinaron mediante un Perkin-Elmer MHS-FIAS acoplado con un espectrofotómetro PerkinElmer, 4100 ZL. Los otros metales traza fueron medidos utilizando espectrofotometría de absorción atómica de horno de grafito (PerkinElmer, $4100 \mathrm{ZL}$ ). Los resultados se expresaron como $\mathrm{mg} \mathrm{kg}^{-1}$ de sedimento seco. El procedimiento analítico fue controlado usando material de referencia (MESS-I NRC y CRM 277 $\mathrm{BCR}$ ). 


\section{Interstitial water extraction}

An aliquot of approximately $3 \mathrm{~L}$ of sample was obtained $24 \mathrm{~h}$ after the last collection of sediments. Glass centrifuge tubes were filled with sediment aliquots for each station, collected from the nine sites. Sediment weight per tube ranged from 90 to $110 \mathrm{~g}$, depending on sediment composition and pore water content. Interstitial water was extracted from sediments by centrifugation $2600 \times \mathrm{g}$ for $2 \mathrm{~h}$ at $2^{\circ} \mathrm{C}$ (Ankley and Schubauer-Berigan, 1994). The supernatant was placed in a $500-\mathrm{mL}$ borosilicate Erlenmeyer flask and maintained in the dark at $4^{\circ} \mathrm{C}$ until used (approximately $48 \mathrm{~h}$ ).

\section{Sediment toxicity tests}

Six separate sediment bioassays were used to measure sediment toxicity. Tests were chosen to signal toxicity over a wide range of taxa and biological processes (table 1). Wholesediment toxicity tests were conducted with the estuarine amphipod Microdeutopus gryllotalpa (10 d static: survival [DelValls ct al., 1994], following the recommendations by ASTM, 1993) and the estuarine clam Ruditapes philippinarum (48 h static: reburial [DelValls et al., 1994], following the recommendations of McGreer, 1979). Interstitial water toxicity tests were conducted with populations of the estuarine rotifer Brachionus plicatilis ( $7 \mathrm{~d}$ static: population decline [DelValls et al., 1996, 1997]) and of the marine bacteria Photobacterium phosphoreum (Microtox ${ }^{\circledR}$ toxicity test [Bulich, 1981], with modifications reported by DelValls et al., 1997).

Sediment elutriate toxicity tests were conducted with two different species: larvae of the estuarine bivalve Crassostrea angulata $(48 \mathrm{~h}$ static: survival [DelValls, 1994], following the recommendations by APHA, 1985) and larvae of the marine fish Sparus aurata. This last sediment toxicity test has not been previously described. Briefly, larvae were obtained from eggs at CUPIMAR S.A. and hatched in our laboratory (Instituto de Ciencias Marinas de Andalucia, CSIC) at $19.5 \pm 0.5^{\circ} \mathrm{C}$ and continuous light (3000 lux), following the steps outlined by Polo (1991). Individuals selected

\section{Tests de toxicidad}

La temperatura, salinidad y el oxígeno disuelto (método de Winkler) fueron medidos durante los tests de toxicidad en cada uno de los bioensayos.

\section{Obtención de los extractos de sedimento}

Se obtuvieron alícuotas $(3 \mathrm{~L})$ de sedimento $24 \mathrm{~h}$ después de la última recolección de sedimento para cada una de las estaciones en los nueve lugares (siete estaciones y los dos controles de toxicidad negativo y positivo), que fueron transferidos a contenedores de vidrio de $10 \mathrm{~L} \mathrm{y}$ fueron diluidos con agua de mar limpia en una proporción $1: 2 \mathrm{v} / \mathrm{v}$; se mantuvieron durante $48 \mathrm{~h}$ en agitación, seguido de un proceso de decantación durante $24 \mathrm{~h}$. Después de esto, el sobrenadante fue cuidadosamente decantado y preparado para ser utilizado en cada uno de los tests de toxicidad que se desarrollaron sobre el extracto de sedimento.

\section{Obtención del agua intersticial}

Un alícuota de aproximadamente $3 \mathrm{~L}$ de muestra fue obtenido $24 \mathrm{~h}$ después de la última recolección de sedimento. Los tubos de centrífuga de vidrio se llenaron con alícuotas de sedimento de cada estación muestreada en los nueve lugares. El peso de sedimento por tubo oscilaba entre 90 y $110 \mathrm{~g}$, y dependía de la composición del sedimento y del contenido de agua intersticial. El agua intersticial fue obtenida de los sedimentos por centrifugación $2600 \times \mathrm{g}$ durante $2 \mathrm{~h}$ a $2^{\circ} \mathrm{C}$ de temperatura (Ankley y Schubauer-Berigan, 1994). El sobrenadante fue colocado en un frasco Erlenmeyer de vidrio y mantenido en la obscuridad a $4^{\circ} \mathrm{C}$ hasta su utilización (aproximadamente $48 \mathrm{~h}$ ).

\section{Tests de toxicidad de sedimento}

Para medir la toxicidad de los sedimentos se emplearon seis bioensayos de sedimento por separado. Los tests se eligieron para determinar la toxicidad sobre un amplio rango de taxa y procesos biológicos (tabla 1). Los tests de toxicidad de sedimento sobre sedimento bruto se 
Table 1. Summarized description of sediment bioassays perfomed in this study (organism type, sediment:water ratio, temperature, duration and endpoint evaluated). The sediment:water ratio is shown as v:v relation. The IW represents the toxicity tests in which interstitial water was used.

Tabla 1. Descripción resumida de los bioensayos de sedimento llevados a cabo en este estudio (tipo de organismos, cociente sedimento y agua, temperatura, tiempo de duración y respuesta evaluada). La relación sedimento y agua es mostrada como relación v:v. El símbolo IW representa aquellos tests de toxicidad en los cuales se utilizó agua intersticial.

\begin{tabular}{|c|c|c|c|c|}
\hline Sediment toxicity test & $\begin{array}{l}\text { Sediment: } \\
\text { water }\end{array}$ & Temperature & Duration & Endpoints \\
\hline $\begin{array}{l}\text { Microdeutopus gryllotalpa } \\
\text { (adult amphipod) }\end{array}$ & $1: 4$ & $20^{\circ} \mathrm{C}$ & $10 \mathrm{~d}$ & Survival $(\%)$ \\
\hline $\begin{array}{l}\text { Crassostrea angulata } \\
\text { (bivalve larvae) }\end{array}$ & $1: 4$ & $20^{\circ} \mathrm{C}$ & $48 \mathrm{~h}$ & Survival $(\%)$ \\
\hline $\begin{array}{l}\text { Ruditapes philippinarum } \\
\text { (juvenile bivalve) }\end{array}$ & $1: 1.5$ & $20^{\circ} \mathrm{C}$ & $48 \mathrm{~h}$ & $\begin{array}{l}\text { Clam reburial } \\
\qquad\left(\mathrm{ET}_{50}[\mathrm{~h}]\right)\end{array}$ \\
\hline $\begin{array}{l}\text { Brachionus plicatilis } \\
\quad \text { (rotifer population) }\end{array}$ & IW & $25^{\circ} \mathrm{C}$ & $7 \mathrm{~d}$ & $\begin{array}{l}\text { Population decline } \\
\qquad\left(\mathrm{TL}_{50}[\mathrm{~h}]\right)\end{array}$ \\
\hline $\begin{array}{l}\text { Sparus aurata } \\
\quad \text { (fish larvae) }\end{array}$ & $1: 4$ & $20^{\circ} \mathrm{C}$ & $48 \mathrm{~h}$ & Survival (\%) \\
\hline $\begin{array}{l}\text { Photobacterium phosphoreum } \\
\text { (bacteria population) }\end{array}$ & IW & $15^{\circ} \mathrm{C}$ & $15 \mathrm{~m}$ & $\begin{array}{l}\text { Luminiscence decrease } \\
\qquad\left(\mathrm{EC}_{50}[\%]\right)\end{array}$ \\
\hline
\end{tabular}

for the test were less than $4 \mathrm{~mm}$ in size. Usual survival in $S$. aurata populations cultured is in a range between $85 \%$ and $90 \%$ (Polo, 1991). The toxicity test was performed during $48 \mathrm{~h}$ with an initial larvae density of 50 individuals per milliliter, exposed to a constant temperature of $19.5 \pm 0.5^{\circ} \mathrm{C}$ in the photoperiod room $(12 \mathrm{~h}$ both light and dark, with a luminosity of 1000 to 1500 lux), and they were not fed. Aeration was provided to maintain adequate oxygen concentrations ( $80 \%$ saturation). At the end of the assay, surviving individuals were collected by means of a $500-\mu \mathrm{m}$ diameter mesh and counted.

\section{Data calculation and statistical analysis}

Negative control was conducted for all bioassays, whereas positive control was performed for all of them except for the 48-h clam reburial bioassay. All the tests and controls were performed in duplicate. The resulting parameters calculated from each of the seven sediment tests and control duplicates, i.e., percent amphipod survival, clam reburial rates llevaron a cabo con el anfípodo de estuario Microdeutopus gryllotalpa (10 d estático: supervivencia [DelValls et al., 1994], siguiendo las recomendaciones hechas por ASTM, 1993) y la almeja de estuario Ruditapes philippinarum (48 h estático: entarramiento [DelValls et al., 1994], siguiendo las recomendaciones hechas por McGreer, 1979). Los tests de toxicidad sobre agua intersticial se realizaron utilizando poblaciones del rotífero de estuario Brachionus plicatilis ( $7 \mathrm{~d}$ estático: decaimiento de la población [DelValls et al., 1996, 1997]) y poblaciones de la bacteria marina Photobacterium phosphoreum (Microtox ${ }^{\circledR}$ test, [Bulich, 1981], con modificaciones según DelValls et al, 1997).

Los tests de toxicidad sobre extracto fueron llevados a cabo con dos especies diferentes: larvas del bivalvo de estuario Crassostrea angulata (48 h estático: supervivencia [DelValls, 1994], siguiendo las recomendaciones realizadas por APHA, 1985) y larvas del pez. marino Sparus aurata. Este último test de toxicidad no ha sido previamente descrito. De 
$\left(\mathrm{ET}_{50}[\mathrm{~h}]\right)$, percent bivalve larvae survival, percent fish larvae survival, rotifer decline rates $\left(\mathrm{TL}_{50}[\mathrm{~h}]\right)$ and Microtox ${ }^{\star}$ effective sample percent $\left(\mathrm{EC}_{5_{0}}[\%]\right)$, were compared using ANOVA and Scheffe's $F$ tests to identify significant differences in sensitivity among toxicity tests and controls $(P<0.01)$.

The contamination and toxicity data were analyzed by factor analysis, using $\mathrm{PC}$ as the extraction procedure, which is a multivariate statistical technique to explore variable (chemical concentrations, $n=17$; toxicity data, $n=3$ ) distributions. The factor analysis was performed on the correlation matrix, i.e., the variables were autoscaled (standardized) so as to be treated with equal importance. All analyses were performed using the PCA option of the FACTOR procedure, followed by the basic setup for factor analysis procedure (P4M) from the BMDP statistical software package (Frane et al., 1985). All biological data were treated similarly, assuming that the significance of each type of toxicity test was equal. The six toxicity data sets were transformed to show an increase with biological damage; for example, the time required for $50 \%$ of the population to decline $\left(\mathrm{TL}_{50}\right)$ increases when toxicity decreases. For this reason, the parameters calculated from all the tests, except the $\mathrm{ET}_{50}$ from the clam reburial bioassay, were transformed as the inverse $\left(\mathrm{TL}_{50}{ }^{-1}, \mathrm{EC}_{50}{ }^{-1}\right.$ and the survival percents, $\%^{-1}$ ), which in this form increases as toxicity increases.

Adequate quality assurance/quality control (QA/QC) measures were followed in all aspects of the study, from field sampling to laboratory and data entry, following those outlined by Chapman (1988), ASTM (1991, 1993) and Luoma and Ho (1992)

\section{RESULTS AND DISCUSSION}

\section{Sediment chemistry}

As can be observed from the grain size analyses (table 2), sediment samples had relatively similar textures, being dominatcd by the clay fraction with a dark color and with a specific surface ranging from 5.78 to una forma resumida, las larvas se obtuvieron a partir de huevos cedidos por la empresa de acuicultura marina CUPIMAR S.A. e inducidos a la puesta en nuestro laboratorio (Instituto de Ciencias Marinas de Andalucia, CSIC) a una temperatura de $19.5 \pm 0.5^{\circ} \mathrm{C}$ y luz continua (3000 lux), siguiendo los pasos descritos por Polo (1991). Los individuos seleccionados para desarrollar el test fueron menores de $4 \mathrm{~mm}$ en tamaño. La supervivencia usual en poblaciones cultivadas de $S$. aurata de esta edad se encuentra en el intervalo entre $85 \%$ y $90 \%$ (Polo, 1991). El test de toxicidad se llevó a cabo durante $48 \mathrm{~h}$, con una densidad inicial de larvas de 50 individuos por mililitro, expuesta a una temperatura constante de $19.5 \pm 0.5^{\circ} \mathrm{C}$ en la habitación de fotoperiodo ( $12 \mathrm{~h}$ para obscuridad y $12 \mathrm{~h}$ también para luz, con una luminosidad de 1000 a 1500 lux), y no fueron alimentados. La aireación se suministró para mantener concentraciones adecuadas de oxígeno ( $80 \%$ de saturación). Al final del ensayo, los individuos supervivientes fueron obtenidos utilizando una malla con un diámetro en el paso de luz de $500 \mu \mathrm{m}$ y fueron finalmente contados.

\section{Análisis estadístico y cálculo de datos}

El control negativo de toxicidad se llevó a cabo para todos los bioensayos, mientras que el positivo fue llevado a cabo para todos excepto para el ensayo de $48 \mathrm{~h}$ de enterramiento de almejas. Los parámetros calculados para cada uno de los siete sedimentos utilizados en los tests y los dos controles, todos por duplicado, i.e., porcentaje de supervivencia de anfipodos, tasa de enterramiento de almejas $\left(\mathrm{ET}_{50}[\mathrm{~h}]\right)$, porcentaje de supervivencia de larvas de bivalvo, porcentaje de supervivencia de larvas de pez, tasa de decaimento de población de rotífero $\left(\mathrm{TL}_{50}[\mathrm{~h}]\right)$ y porcentaje de muestra efectiva Microtox ${ }^{(}$ $\left(\mathrm{EC}_{50}[\%]\right)$, fueron comparados utilizando tests de comparación ANOVA y $F$ de Scheffe para identificar las diferencias significativas en sensibilidad entre tests y controles $(P<0.01)$.

Los datos de contaminación y toxicidad fueron analizados por análisis de factores utilizando componentes principales (PC) como procedimiento de extracción, que es una técnica 
Table 2. Granulometric content (\%), mean grain size $\eta(n=10)$, and specific surface $\sigma(n=10)$ of surface sediments in littoral ecosystems of the Gulf of Cádiz.

Tabla 2. Contenido granulométrico (\%), tamaño de grano medio $\eta(n=10)$ y superficie específica $\sigma$ $(n=10)$ de sedimentos superficiales en ecosistemas litorales del Golfo de Cádiz.

\begin{tabular}{llllccc}
\hline Station & $>200 \mu \mathrm{m}$ & $20-200 \mu \mathrm{m}$ & $2-20 \mu \mathrm{m}$ & $<2 \mu \mathrm{m}$ & $\eta(\mu \mathrm{m})$ & $\sigma\left(\mathrm{m}^{2} \mathrm{~cm}^{-3}\right)$ \\
\hline CB1 & $0.4 \pm 0.1$ & $0.6 \pm 0.1$ & $21.3 \pm 9.9$ & $77.2 \pm 10.8$ & $3.5 \pm 0.7$ & $7.63 \pm 0.07$ \\
CB2 & $0.4 \pm 0.15$ & $0.5 \pm 0.1$ & $22.0 \pm 7.7$ & $77.0 \pm 7.7$ & $4.1 \pm 0.6$ & $7.35 \pm 0.15$ \\
CB3 & $0.5 \pm 0.1$ & $0.6 \pm 0.1$ & $19.2 \pm 6.7$ & $79.7 \pm 6.9$ & $4.2 \pm 0.9$ & $7.96 \pm 0.14$ \\
CB4 & $0.2 \pm 0.0$ & $0.3 \pm 0.0$ & $18.2 \pm 5.5$ & $80.8 \pm 5.7$ & $3.4 \pm 1.1$ & $7.16 \pm 0.24$ \\
CB5 & $0.4 \pm 0.0$ & $0.2 \pm 0.0$ & $21.1 \pm 0.0$ & $78.3 \pm 0.0$ & $3.5 \pm 0.0$ & $7.03 \pm 0.37$ \\
BR1 & $0.3 \pm 0.1$ & $6.7 \pm 0.0$ & $45.2 \pm 4.9$ & $53.6 \pm 5.0$ & $4.5 \pm 0.7$ & $5.78 \pm 0.11$ \\
BR2 & $0.3 \pm 0.0$ & $0.6 \pm 0.0$ & $18.6 \pm 4.9$ & $80.6 \pm 5.6$ & $3.9 \pm 0.9$ & $7.77 \pm 0.28$ \\
\hline
\end{tabular}

$7.96 \mathrm{~m}^{2} \mathrm{~cm}^{-3}$. Station BR1 was the only station where the sand proportion was higher $(7 \%)$ than the others $(1 \%)$ and the specific surface was lower than the others $\left(5.78 \mathrm{~m}^{2} \mathrm{~cm}^{-3}\right)$. Also, this station presented the highest average grain size value $(4.5 \pm 0.7 \mu \mathrm{m})$.

Summarized concentrations of selected contaminants and elemental analysis are shown in table 3. Levels of organic matter in sediments were similar among them and in the normal range for shallow littoral ecosystems (1-3\% dry weight), except for station BR1 where the value was lower $(0.59 \%)$. A few differences in the concentration of the major elements ( $\mathrm{Fe}$ and Mn) were observed among stations. Of all the stations, BR 1 showed the lowest values for both metals. In general, chemical concentrations were relatively higher in sediments from the Bay of Cádiz than those from the Barbate River and were similar to concentrations previously reported for both systems (Gómez-Parra et al., 1984; Establier et al., 1985). Station CB2 was highly enriched in domestic detergents (LAS) and inorganic contaminants typical from urban effluents (high levels of $\mathrm{Pb}$ and $\mathrm{Ag}$ ), compared to the other stations. Stations $\mathrm{CB} 3$ and $\mathrm{CB} 5$ were more contaminated with chemicals from industrial and marine activities, such as $\mathrm{Hg}$, As and $\mathrm{Sn}$, and station $\mathrm{CB} 5$ was contaminated with Cr. At station CB4, several heavy metals (Fe, $\mathrm{Mn}, \mathrm{Cd}, \mathrm{Ag}, \mathrm{Hg}, \mathrm{Ni}$ and $\mathrm{Co}$ ) were found in higher concentrations in sediments than at the reference station (CB1). estadistica multivariante para explorar distribuciones de variables (concentraciones químicas, $n=17$; datos de toxicidad, $n=3$ ). El análisis de factores fue llevado a cabo sobre la matriz de correlación; las variables se autoescalaron (estandarizaron) para ser consideradas de igual importancia. Todos los análisis fueron realizados utilizando la opción PCA del procedimiento FACTOR, seguido por el procedimiento básico para un caso de análisis de factores (P4M) utilizando el paquete estadísitico informático BMDP (Frane et al., 1985). Todos los datos biológicos fueron tratados de un modo igual, asumiendo que cada tipo de test tiene la misma importancia. Las series de datos de los seis ensayos de toxicidad se transformaron para mostrar un aumento con el daño biológico; por ejemplo, en el ensayo de rotíferos, el tiempo requerido por el $50 \%$ de la población para decaer $\left(\mathrm{TL}_{50}\right)$ aumenta cuando la toxicidad disminuye. Por esta razón, los parámetros fueron recalculados para todos los tests, excepto para el enterramiento de almejas, transformándolos en su inversa $\left(\mathrm{TL}_{50}{ }^{-1}, \mathrm{EC}_{50}{ }^{-1}\right.$ y los porcentajes de supervivencia, $\%^{-1}$ ); de esta forma aumentan cuando la toxicidad lo hace.

En todos los aspectos del estudio se siguieron las adecuadas medidas de control de calidad (QA/QC), desde el muestreo en el campo hasta los procedimientos en el laboratorio y los de cálculo, siguiendo las recomendaciones de Chapman (1988), ASTM (1991, 1993) y Luoma y Ho (1992) 
Table 3. Values of the concentrations of total organic carbon (OC, \%), total carbon (\%), total nitrogen $(\%), 14$ heavy metals ( $\mathrm{Fe}, \mathrm{Mn}, \mathrm{Zn}, \mathrm{Cu}, \mathrm{Pb}, \mathrm{Cd}, \mathrm{Cr}, \mathrm{Ag}, \mathrm{Hg}, \mathrm{V}, \mathrm{Ni}, \mathrm{Co}, \mathrm{As}$ and $\mathrm{Sn} ; \mathrm{mg} \mathrm{kg}^{-1}$ dry weight; $\mathrm{Fe}, \%$ ), and the linear alkylbenzenesulphonate (LAS; $\mathrm{mg} \mathrm{kg}^{-1}$ dry weight), analyzed in sediments from the stations selected in the Gulf of Cádiz.

Tabla 3. Valores de las concentraciones de carbono orgánico total (OC, \%), carbono total (\%), nitrógeno total (\%), 14 metales traza ( $\mathrm{Fe}, \mathrm{Mn}, \mathrm{Zn}, \mathrm{Cu}, \mathrm{Pb}, \mathrm{Cd}, \mathrm{Cr}, \mathrm{Ag}, \mathrm{Hg}, \mathrm{V}, \mathrm{Ni}, \mathrm{Co}, \mathrm{As}$ y $\mathrm{Sn}$; $\mathrm{mg} \mathrm{kg}{ }^{-1}$ de peso seco; $\mathrm{Fe}$, \%), y el alquilbencenosulfonato lineal (LAS; $\mathrm{mg} \mathrm{kg}^{-1}$ de peso seco), analizadas en sedimentos de las estaciones seleccionadas en el Golfo de Cádiz.

\begin{tabular}{lccccccc}
\hline Chemical & CB1 & CB2 & CB3 & CB4 & CB5 & BR1 & BR2 \\
\hline $\mathrm{OC}$ & 1.39 & 2.96 & 2.21 & 1.82 & 2.46 & 0.59 & 1.86 \\
Total carbon & 2.98 & 3.75 & 3.79 & 3.49 & 3.61 & 3.17 & 1.96 \\
Total nitrogen & 0.10 & 0.19 & 0.14 & 0.07 & 0.10 & 0.03 & 0.12 \\
$\mathrm{Fe}$ & 2.77 & 3.34 & 3.19 & 3.34 & 2.77 & 1.27 & 3.98 \\
$\mathrm{Mn}$ & 333 & 278 & 332 & 452 & 272 & 262 & 295 \\
$\mathrm{Zn}$ & 82 & 157 & 163 & 73 & 105 & 34 & 140 \\
$\mathrm{Cu}$ & 51.4 & 69.6 & 66.4 & 34.8 & 49.6 & 37.4 & 73.7 \\
$\mathrm{~Pb}$ & 30.5 & 84.6 & 64.4 & 24.4 & 51.1 & 66.8 & 30.0 \\
$\mathrm{Cd}$ & 0.51 & 0.67 & 0.75 & 0.99 & 0.81 & 1.10 & 0.68 \\
$\mathrm{Cr}$ & 49.6 & 77.1 & 53.0 & 41.1 & 283.9 & 42.5 & 101.2 \\
$\mathrm{Ag}$ & 0.48 & 1.34 & 1.20 & 0.78 & 1.06 & 0.75 & 0.61 \\
$\mathrm{Hg}$ & 0.11 & 0.25 & 0.46 & 0.25 & 0.57 & 0.06 & 0.15 \\
$\mathrm{~V}$ & 79.1 & 106.5 & 77.0 & 80.7 & 83.3 & 17.9 & 147.5 \\
$\mathrm{Ni}$ & 24.9 & 35.5 & 27.9 & 34.4 & 32.5 & 8.2 & 42.8 \\
$\mathrm{Co}$ & 7.29 & 9.16 & 7.64 & 10.92 & 7.78 & 3.40 & 11.50 \\
$\mathrm{As}$ & 11.27 & 7.72 & 13.69 & 8.53 & 13.24 & 5.19 & 9.67 \\
$\mathrm{Sn}$ & 19.8 & 17.0 & 24.0 & 9.9 & 18.8 & 7.4 & 10.3 \\
$\mathrm{LAS}$ & 2.2 & 62.1 & 12.8 & 2.6 & 1.2 & 1.7 & 2.5 \\
\hline
\end{tabular}

Although these data were ideal to identify the origin of contamination in the area studied (DelValls et al., in press), they offer a limited picture of the changes that may have occurred as a result of anthropogenic impacts in the Gulf of Cádiz (Arjonilla et al., 1994). This also demonstrates the difficulty of using chemical data alone to define problem areas, because the resulting data provide little or no evidence of biological consequences of the contamination.

\section{Sediment toxicity}

There were no significant differences among replicates for any water quality parameters (temperature, salinity and dissolved

\section{RESULTADOS Y DISCUSIÓN}

\section{Química del sedimento}

Como puede observarse a partir de los análisis del tamaño de grano (tabla 2), las muestras de sedimento presentan textura relativamente similar, estando dominadas por la fracción arcillosa con un color obscuro y con valores de la superficie específica en el intervalo de 5.78 a $7.96 \mathrm{~m}^{2} \mathrm{~cm}^{-3}$. La estación BR1 fue la única que presentó una proporción de arena mayor $(7 \%)$, comparada con las otras estaciones (1\%), y el valor de la superficie especifica fue menor que en el resto 
oxygen) measured in all toxicity tests $(P<$ 0.05 ). Summarized bioassay results are shown in figure 3. Blank chambers containing only filtered oceanic seawater (SW) and interstitial water and clean sediment (CN) were not toxic during test exposures, with toxic effect ranging from $5 \%$ to $0 \%$ in all the tests. Detailed results are reported by DelValls (1994) and DelValls et al. $(1994,1996,1997)$.

\section{Whole sediment toxicity testing}

\section{Clam reburial}

There were no clam mortalities in any of the test or control sediments over the 48-h exposure period. The $E T_{50}$ values were fastest in the salt marsh of the Barbate River stations (BR\#) and at stations CBI and CB5 in the Bay of Cádiz, slowest at station $\mathrm{CB} 2$, and intermediate at stations $\mathrm{CB} 3$ and $\mathrm{CB} 4$. Stations $\mathrm{CB} 2, \mathrm{CB} 3$ and $\mathrm{CB} 4$ were significantly different from the negative control $(P<0.05)$.

\section{Amphipod survival}

Mean survival during the 10-day amphipod bioassay ranged from $0 \%$ in the positive control, low (16\%) at station CB2, to $85 \%$ at CB1. The highest mean survival was in the sediment control (97.5\%). Survival in sediments CB3, $\mathrm{CB} 5$ and $\mathrm{CB} 2$ was significantly different from the negative control $(P<0.05)$. Station CB2 survival was not significantly different to the positive control $(P<0.05)$.

\section{Sediment elutriate toxicity testing}

Bivalve larvae survival

Mean survival during the 48 -h bivalve larvae toxicity test, relative to the seawater negative control (SW), ranged from $15.8 \%$ in $\mathrm{CB} 2$ elutriates to $95 \%$ in BR1 elutriates. The concentration of larvae in the control (SW) was defined as $100 \%$; the mortality measured in this control was less than $5 \%$. Mean relative survival in the sediment negative control $(\mathrm{CN})$ and in the sediment positive control (CP) was $\left(5.78 \mathrm{~m}^{2} \mathrm{~cm}^{-3}\right)$. También, esta estación presentó el mayor de los valores medios en el tamaño de grano $(4.5 \pm 0.7 \mu \mathrm{m})$.

Un resumen de los valores de concentración de los contaminantes seleccionados y del resultado del análisis elemental aparece en la tabla 3. Los niveles de materia orgánica en los sedimentos fueron similares entre ellos y en el intervalo normal para ecosistemas litorales someros ( $1-3 \%$ de sedimento seco), excepto para la estación BR1 donde los valores fueron menores $(0.59 \%)$. Se observaron pequeñas difcrencias entre estaciones en las concentraciones de los elementos mayoritarios (Fe y $\mathrm{Mn}$ ). De todas las estaciones, BRI mostraba el menor valor para ambos metales. En general, las concentraciones de contaminantes fueron relativamente mayores en los sedimentos de la Bahía de Cádiz que en aquellos de la zona del río Barbate $y$ en el intervalo similar a aquellas concentraciones reportadas previamente para ambos ecosistemas (Gómez-Parra et al., 1984; Establier et al., 1985). La estación CB2 estaba altamente enriquecida en detergentes domésticos (LAS) y contaminantes inorgánicos típicos de efluentes urbanos (niveles altos de $\mathrm{Pb}$ y $\mathrm{Ag}$ ), comparada con las estaciones CB3 y CB5, más contaminadas con contaminantes de orígen industrial y de actividades marinas como $\mathrm{Hg}$, As y Sn, y la estación CB5, más contaminada con Cr. En la estación CB4 se encontraron varios metales pesados ( $\mathrm{Fe}, \mathrm{Mn}, \mathrm{Cd}, \mathrm{Ag}, \mathrm{Hg}, \mathrm{Ni}$ y $\mathrm{Co}$ ), con mayores concentraciones en sus sedimentos que en aquellos provenientes de la estación de referencia (CB1).

Aunque estos datos fueron ideales para identificar el origen de la contaminación en el área estudiada (DelValls et al., en prensa), solamente ofrecen una imagen limitada de los cambios que podrían estar ocurriendo como un resultado de los impactos antropogénicos en el Golfo de Cádiz (Arjonilla et al., 1994). Esto también demuestra la dificultad de utilizar los datos químicos por sí solos para definir áreas con problemas, debido a que los datos resultantes ofrecen una pequeña $o$ ninguna evidencia de las consecuencias biológicas asociadas con los fenómenos de contaminación. 


\section{INCREASED TOXICITY}

Whole sediment
Clam reburial
$\mathrm{ET}_{50}(\mathrm{~h})$
Amphipod survival
$\%$ Survival
Elutriate sediment
Bivalve survival
$\%$ Survival
Fish survival
$\%$ Survival
Interstitial water
Rotifer population
$\mathrm{TL}_{50}$ (h)
Microtox test
EC ${ }_{50}(\%)$

\author{
NC BR1 BR2 CB1 CB5 CB4 CB3 CB2 \\ $\begin{array}{llllllll}0.015 & 0.985 & 2.802 & 5.602 & 8.661 & 10.776 & 11.599 & >48\end{array}$
}

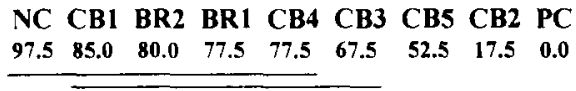

SW NC CB1 CB4 BR2 BR1 CB3 CB2 CB5 PC

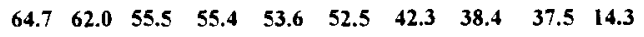

SW NC CB1 CB4 BR1 BR2 CB3 CB5 CB2 PC $>100>100>100>100>100>100>100>1004.51 .2$

Figure 3. Summary of the results of the toxicity tests (mean values). Treatments not underlined by the same line are significantly different at $P<0.05$ (Scheffe's $F$ tests).

Figura 3. Resumen de los resultados de los tests de toxicidad (valores medios). Los tratamientos no unidos por la misma línea son significativamente diferentes con $P<0.05$ (tests $F$ de Scheffe).

$96.2 \%$ and $0.5 \%$ of the seawater control, respectively. All stations, except those from the salt marsh of the Barbate River, were significantly different $(P<0.05)$ from both negative controls ( $\mathrm{SW}$ and $\mathrm{CN}$ ). All the stations were significantly different $(P<0.05)$ from the positive control.

Fish larvae survival

Mean survival during the 48 -h fish larvae toxicity test, relative to the sediment ncgative

\section{Toxicidad de sedimentos}

No se apreciaron diferencias significativas entre los distintos replicados para cualquiera de los parámetros de calidad de agua (temperatura, salinidad y oxígeno disuelto) medidos en todos los tests de toxicidad $(P<0.05)$. Un resumen de los resultados de los bioensayos se ofrece en la figura 3. No se midió toxicidad en los contenedores blancos que contenian sólo agua de mar oceánica filtrada (SW) y agua intersticial, así como scdimento limpio (CN), 
control (defined as above), ranged from a low of $0.5 \%$ in CB2 elutriates to a high of $79 \%$ in BR1 elutriates. Mean relative survival in the oceanic seawater negative control and in the sediment positive control was $94.9 \%$ and $0 \%$, respectively. All Bay of Cádiz sediment elutriates had significantly $(P<0.05)$ lower survivals than the sediment and seawater controls. The BR\# elutriates were significantly $(P<0.05)$ similar to the seawater negative control.

\section{Interstitial water toxicity testing}

Rotifer population decline

Mean $\mathrm{TL}_{50}$ values for negative controls (interstitial $[\mathrm{CN}]$ and seawater [SW]) were the slowest, while those obtained for the positive interstitial water control were the fastest. Mean $\mathrm{TL}_{50}$ for the toxicity test stations showed the following trends: fastest at stations CB5 and $\mathrm{CB} 2$, slowest at stations $\mathrm{CB} 1, \mathrm{CB} 4$ and $\mathrm{BR \# \text {, }}$ and intermediate at station CB3. Only stations CB2 and CB5 were significantly different $(P<0.05)$ from both negative controls, and CB3 was significantly different $(P<0.05)$ from the seawater negative control.

Microtox bioassay

Mean $\mathrm{EC}_{50}$ values in negative controls (interstitial $[\mathrm{CN}]$ and seawater [SW]) were higher than $100 \%$, while the value in the positive interstitial water control was the lowest $(1.2 \%)$. Only $\mathrm{CB} 2$ interstitial water had an $\mathrm{EC}_{50}$ value significantly different $(P<0.05)$ from the negative controls.

The data from all bioassay endpoints indicate that station CB2 sediments were significantly more toxic $(P<0.05)$ than those from the rest of the stations in the Gulf of Cádiz. Also, the interstitial water rotifer ( $B$. plicatilis) assay endpoint indicated that station CB5 was as toxic as station $\mathrm{CB} 2$. Based on the above results (fig. 3), we conclude that sediments at station CB2 were highly toxic, those at CB3 and CB5 moderately toxic, and those at CB4 and CB1 showed almost no toxicity (similar to clean sediment of the control, in five of the six bioassays). presentando un intervalo en el porcentaje de efecto tóxico entre $0 \%$ y $5 \%$ para todos los tests. Los resultados detallados de cstos tests son reportados por DelValls (1994) y DelValls et al. (1994, 1996, 1997).

\section{Toxicidad del sedimento bruto}

\section{Enterramiento de almejas}

No se apreció mortalidad en ninguno de los tests o de los controles de sedimento durantc las $48 \mathrm{~h}$ de periodo de exposición. Los valores de $\mathrm{ET}_{50}$ fueron los más rápidos en las estaciones del río Barbate (BR\#) y en las estaciones CB1 y CB5 localizadas en la Bahía de Cádiz, siendo los más lentos en la estación CB2, e intermedios en las estaciones CB3 y CB4. Las estaciones $\mathrm{CB} 2, \mathrm{CB} 3$ y $\mathrm{CB} 4$ fueron significativamente diferentes del control negativo $(P<0.05)$.

\section{Supervivencia de anfípodos}

La supervivencia media durante los 10 días del bioensayo de anfípodos se encontró en el intervalo entre $0 \%$ para el control positivo, siendo baja (16\%) en la estación CB2, y $85 \%$ en la estación CB1. La mayor de las supervivencias medias fue registrada en el control negativo de sedimento $(97.5 \%)$. La supervivencia en los sedimentos CB3, CB5 y CB2 fue significativamente diferente del control negativo $(P<0.05)$. La supervivencia en la estación CB2 no fue significativamente diferente del control positivo $(P<0.05)$.

\section{Toxicidad de los extractos de sedimento}

Supervivencia de larvas de bivalvo

La supervivencia media durante las $48 \mathrm{~h}$ de duración del ensayo de toxicidad de larvas de bivalvo, relativa al control negativo de agua de mar (SW), se midió en el intervalo de $15.8 \%$ en los extractos de la estación CB2 y de $95 \%$ en los extractos de la estación BR1. La concentración de larvas en el control (SW) fue definida como de $100 \%$ y la mortalidad real medida en este control fue siempre menor que 


\section{Statistical analysis for linking toxicity and chemistry data}

In order to compare the toxicity tests and to establish adverse effect levels of chemical concentrations in sediments, we applied factor analysis to quantitatively determine those relationships among the variables and the cases studied (Bulger et al., 1993; Zitko, 1994; DelValls and Chapman, in press). The application of multivariate analysis to the variables in this study indicates that 23 variables, 17 chemical concentrations in sediments (organic carbon $[\mathrm{OC}]$, specific surface, $\mathrm{Fe}, \mathrm{Mn}, \mathrm{Zn}, \mathrm{Cu}$, $\mathrm{Pb}, \mathrm{Cd}, \mathrm{Cr}, \mathrm{Ag}, \mathrm{Hg}, \mathrm{V}, \mathrm{Ni}, \mathrm{Co}, \mathrm{As}, \mathrm{Sn}$, and LAS) and 6 endpoints from toxicity tests (\% survival ${ }^{-1}$ m grvllotalpa), $\mathrm{ET}_{50}[\mathrm{~h}], \%$ survival ${ }^{-1}{ }^{\prime} \mathrm{c}$ angulata, $\%$ survival ${ }^{-1}$ is auratus; $, \mathrm{TL}_{501}\left[\mathrm{~h}^{-1}\right], \mathrm{EC}_{50}{ }^{-1}$ $\left[\%^{-1}\right]$ ), can be represented by five new variables or factors. These new variables explain $93.45 \%$ of the variance in the original data set. The sorted rotated factor loadings are coefficients correlating the original variables and the factors in this analysis. In the present study, we elected to group variables with a particular factor when their loadings were 0.5 or greater (table 4), corresponding to an associated explained variance of more than $50 \%$. This approximates Comrey's (1973) cut-off of 0.55 for a good association between an original variable and a factor, and also takes into account discontinuities in the magnitudes of the loadings of the original variables. Negative values of sorted rotated factor loadings (negative salience) are as important as positive values (positive salience). However, in this analysis, the positive loadings are in general of larger magnitude than the negative loadings. The loadings following varimax rotation for the five factors are given in table 4. Each factor is described according to the dominant group of variables.

Factor 1: Untreated urban discharges as source of contaminants with adverse effects

This factor, accounting for $42.33 \%$ of the total variance, has high positive loadings in the LAS, $\mathrm{Pb}, \mathrm{Ag}$ and $\mathrm{OC}$ sediment concentrations, and all the sediment toxicity test
$5 \%$. La supervivencia relativa media en el sedimento de control negativo y en el sedimento de control positivo fue, respectivamente, $96.2 \%$ y $0.5 \%$. Todas las estaciones, excepto aquellas localizadas en la marisma del río Barbate, fueron significativamente diferentes $(P<0.05)$ de ambos controles negativos (SW y $\mathrm{CN}$ ). Todas las estaciones fueron significativamente diferentes del control positivo $(P<0.05)$.

Supervivencia de larvas de peces

La supcrvivencia media durante las $48 \mathrm{~h}$ de duración del test de toxicidad de larvas de peces, relativa a aquella en el sedimento de control negativo (definida como el ensayo anterior), fue pequeña, de sólo $0.5 \%$ en los extractos de la estación CB2, hasta grande en los extractos de la estación BR1. La supervivencia media relativa en el control negativo con agua de mar oceánica y en el sedimento de control positivo fue $94.9 \%$ y $0 \%$, respectivamente. Todos los extractos de sedimento de la Bahía de Cádiz tuvieron significativamente menores porcentajes de supervivencia $(P<0.05)$ que los controles negativos de sedimento y de agua oceánica. La supervivencia en los extractos de sedimento provenientes de la marisma del río Barbate fue significativamente similar a aquella medida en el control negativo con agua oceánica.

\section{Toxicidad del agua intersticial}

Decaimiento de la población de rotífero

Los valores medios de $\mathrm{TL}_{50}$ para los controles negativos fueron los más lentos, mientras que para el control positivo de toxicidad fueron los más rápidos. Los valores medios de $\mathrm{TL}_{50}$ mostraban las siguientes tendencias en las estaciones: más rápidos en las estaciones $\mathrm{CB} 5$ y CB2, más lentos en las estaciones CB1, CB4 y $B R \#$, e intermedios en la estación CB3. Sólo las estaciones CB2 y CB5 fueron significativamente diferentes $(P<0.05)$ de ambos controles negativos, y la estación CB3 fue significativamente diferente $(P<0.05)$ del control con agua de mar oceánica. 
Table 4. Sorted rotated factor loadings (pattern) of 23 variables for the five principal factors. The loading matrix has been rearranged so that the columns appear in decreasing order of variance explained by factors. Only loadings greater than 0.5 are shown in the table. Factors (\#) are numbercd consecutively from left to right in order of decreasing variance explained.

Tabla 4. Pesos de los factores rotados de 23 variables en los cinco factores principales. La matriz de los pesos ha sido ordenada de forma que en las columnas aparecen en orden de varianza decreciente explicada. Sólo los pesos mayores que 0.5 se muestran en la tabla. Los factores (\#) están numerados conseculivamente de izquierda a derecha a medida que explican menor varianza.

\begin{tabular}{|c|c|c|c|c|c|}
\hline $\begin{array}{l}\text { Variable } \\
\% \text { variance }\end{array}$ & $\begin{array}{c}\# 1 \\
42.36\end{array}$ & $\begin{array}{c}\# 2 \\
23.93\end{array}$ & $\begin{array}{c}\# 3 \\
14.24\end{array}$ & $\begin{array}{c}\# 4 \\
7.22\end{array}$ & $\begin{array}{c}\# 5 \\
5.73\end{array}$ \\
\hline $\mathrm{LAS}\left(\mathrm{mg} \mathrm{kg}^{-1}\right)$ & 0.966 & $\cdots$ & --- & --- & $\cdots$ \\
\hline$\%$ Survival $^{-1}{ }_{\text {(S. auratus) }}$ & 0.963 & -- & -- & -- & --- \\
\hline$\%$ Survival $^{-1}(M$ grvyllotalpa) & 0.952 & --- & --- & -- & -- \\
\hline $\mathrm{EC}_{50}^{-1}\left(\%^{-1}\right)$ & 0.951 & --- & --- & -- & --- \\
\hline $\mathrm{ET}_{50}(\mathrm{~h})$ & 0.947 & --- & $-\cdots$ & --- & --- \\
\hline$\%$ Survival $^{-1}{ }_{(\text {C. angulata })}$ & 0.947 & -- & --- & --- & --- \\
\hline $\mathrm{Pb}\left(\mathrm{mg} \mathrm{kg}^{-1}\right)$ & 0.747 & --- & --- &.-- & -- \\
\hline $\mathrm{Ag}\left(\mathrm{mg} \mathrm{kg}^{-1}\right)$ & 0.718 & --- & 0.591 & $\cdots$ & $\ldots$ \\
\hline $\mathrm{OC}(\%)$ & 0.570 & 0.525 & 0.537 & --- & -- \\
\hline $\mathrm{TL}_{50}\left(\mathrm{~h}^{-1}\right)$ & 0.543 & --- & 0.758 & --- & --- \\
\hline $\mathrm{Ni}\left(\mathrm{mg} \mathrm{kg}^{-1}\right)$ & --- & 0.946 &.- & -- & --- \\
\hline $\mathrm{V}\left(\mathrm{mg} \mathrm{kg}^{-1}\right)$ & --- & 0.944 & --- & --- & -- \\
\hline $\mathrm{Co}\left(\mathrm{mg} \mathrm{kg}^{-1}\right)$ & --- & 0.943 & --- & --- & --- \\
\hline $\mathrm{Fe}(\%)$ & --- & 0.922 & --- & --- & --- \\
\hline Specific surface $\left(\mathrm{m}^{2} \mathrm{~cm}^{-3}\right)$ & --- & 0.671 & $\cdots$ & 0.702 & --- \\
\hline $\mathrm{Zn}\left(\mathrm{mg} \mathrm{kg}^{-1}\right)$ & --- & 0.546 & --- & 0.536 & -- \\
\hline $\mathrm{Cu}\left(\mathrm{mg} \mathrm{kg}^{-1}\right)$ &.-- & 0.537 & $\cdots$ & --- & --- \\
\hline $\mathrm{Hg}\left(\mathrm{IIg} \mathrm{kg}{ }^{-1}\right)$ & --- & --- & 0.925 & -- & --- \\
\hline $\mathrm{Cr}\left(\mathrm{mg} \mathrm{kg}^{-1}\right)$ & --- & -- & 0.813 & -- & --- \\
\hline As $\left(\mathrm{mg} \mathrm{kg}^{-1}\right)$ & --- & --- & 0.545 & 0.715 & --- \\
\hline $\mathrm{Sn}\left(\mathrm{mg} \mathrm{kg}^{-1}\right)$ & $-\cdots$ & --- & --- & 0.882 & --- \\
\hline $\mathrm{Cd}\left(\mathrm{mg} \mathrm{kg}^{-1}\right)$ &.-- & --- & --- & -0.703 & -- \\
\hline $\operatorname{Mn}\left(\mathrm{mg} \mathrm{kg}^{-1}\right)$ & --- & --- & --- & -.- & -0.918 \\
\hline
\end{tabular}

endpoints. The loadings of the $\mathrm{OC}$ sediment concentrations and the rotifer endpoint $\left(\mathrm{TL}_{50}{ }^{-1}\right)$ showed lower values compared to the rest of the variables; these variables also had loadings above 0.5 in other factors (OC, \#2 and \#3; and $\mathrm{TL}_{\varsigma_{11}}{ }^{-1}$, \#3). Clearly, the strong relationship between the sediment concentrations of LAS, $\mathrm{Pb}$ and $\mathrm{Ag}$, typically associated with untreated urban discharges (Bryan and Langston, 1992; González-Mazo et al., 1997), and the biological effects in all loxicity tests, relates this factor to

\section{Ensayo Microtox}

Los valures medios de $\mathrm{EC}_{50}$ en los controles negativos de toxicidad fueron mayores del $100 \%$, mientras que el valor en el control positivo de toxicidad fue el menor (1.2\%). Sólo el agua intersticial de la estación $\mathrm{CB} 2$ tenía un valor de $\mathrm{EC}_{50}$ significativamente diferente $(P<0.05)$ de aquel de los controles negativos de toxicidad. 
municipal-urban point sources with adverse effects.

Factor 2: Geochemical sediment matrix and background levels

This factor, accounting for $23.93 \%$ of the total variance, has positive loadings in the concentrations of the heavy metals $\mathrm{Ni}, \mathrm{V}, \mathrm{Co}$, $\mathrm{Fe}, \mathrm{Zn}$ and $\mathrm{Cu}$, the specific surface, and the total $\mathrm{OC}$ concentration. On the other hand, none was associated with variables indicating biological effects. Based on this association, this factor describes the geochemical matrix composition of the sediments studied represented by $O C$, specific surface and the metal $\mathrm{Fe}$ (iron hydroxides), which are three important parameters controlling the association of chemical to sediments and involved in the geochemical sediment matrix in estuarine and coastal sediments (Luoma, 1990). Also, the heavy metal variables included in the factor association could be related to those background levels reported for the area studied in previous studies (Gómez-Parra et al., 1984; Establier et al., 1985).

Factor 3: Adverse effects of the heavy metals $\mathrm{Hg}$ and $\mathrm{Cr}$ on Brachionus plicatilis

High loadings are observed for the heavy metals $\mathrm{Hg}$ and $\mathrm{Cr}$, and for the biological endpoints in B. plicatilis assay $\mathrm{TL}_{50}{ }^{-1}$ in this factor, which accounts for $14.24 \%$ of the total variance. Also, intermediate positive loadings are shown for $\mathrm{Ag}$ and $\mathrm{As}$. Even though loadings of $\mathrm{Ag}$ and $\mathrm{As}$ were above 0.5 , they were not associated with the adverse effects because they show higher loadings in other factors associated with biological effects $(\mathrm{Ag}$, factor 1) and with no biological effects (As, factor 4). These correlations suggest an adverse effect of dissolved metal concentrations in interstitial water on $B$. plicatilis. $\mathrm{Cr}$ is widely used in metallic surface treatment, as well as in other industrial activities (aircraft and car components) near some of the areas studied; $\mathrm{Hg}$ is also widely used in several industrial processes (Bryan and Iangston, 1992).
Los datos obtenidos en todas las respuestas de los bioensayos indican que los sedimentos de la estación CB2 en la Bahía de Cádiz fueron significativamente más tóxicos $(P<0.05)$ que aquellos del resto de las estaciones en el Golfo de Cádiz. También, la respuesta obtenida en el ensayo sobre el rotífero $B$. plicatilis en el agua intersticial indicaba que la estación CB5 fue tan tóxica como la estación CB2. Basándonos en los resultados descritos (fig. 3), concluimos que los sedimentos de la estación CB2 fueron tóxicos, aquellos de las estaciones CB3 y CB5 moderadamente tóxicos y aquellos de las estaciones CB4 y CB1 no mostraban casi toxicidad (respuesta similar a los controles negativos, en cinco de los seis bioensayos).

\section{Análisis estadístico para ensamblar los datos químicos y de toxicidad}

Para comparar los tests de toxicidad y para establecer los niveles del efecto adverso debido a las concentraciones de contaminantes en los sedimentos, nosotros aplicamos cuantitativamente el análisis de factores para determinar aquellas relaciones entre las variables y los casos elegidos (Bulger et al., 1993; Zitko, 1994; DelValls y Chapman, en prensa). La aplicación del análisis multivariante a las variables utilizadas en este estudio indican que 23 variables, 17 concentraciones en sedimento (carbono orgánico $[\mathrm{OC}]$, superficie específica, $\mathrm{Fe}, \mathrm{Mn}, \mathrm{Zn}$, $\mathrm{Cu}, \mathrm{Pb}, \mathrm{Cd}, \mathrm{Cr}, \mathrm{Ag}, \mathrm{Ig}, \mathrm{V}, \mathrm{Ni}, \mathrm{Co}$, As, Sn y LAS) y 6 respuestas obtenidas de los tests de toxicidad ( $\%$ supervivencia ${ }^{-1}$ M. krythraiapa) ET $_{\text {so }}$ [h]; \% supervivencia ${ }^{-1}$ (c angulata $; \%$ superviven$\left.\mathrm{cia}^{-1}{ }_{(s \text { aurrats } s ;} ; \mathrm{TL}_{50}\left[\mathrm{~h}^{-1}\right] ; \mathrm{EC}_{50}{ }^{-1}\left[\%{ }^{-1}\right]\right)$ pueden ser representadas por cinco variables nuevas o factores. Estas variables nuevas explican el $93.45 \%$ de la varianza en la serie de datos original. Los pesos de los factores rotados son coeficientes que correlacionan las variables originales y los factores en este análisis. En el presente estudio, para agrupar una variable dentro de un determinado factor se selecciona ésta cuando su peso es 0.5 o mayor (tabla 4), correspondiendo a una varianza explicada de más del 50\%. Esto aproxima al corte de Comrey (1973) de 0.55 para una buena 
Factor 4: Contamination associated with nautical recreational activity sources

High positive loadings are observed for Sn and $\mathrm{As}$ and for the specific surface, whereas $\mathrm{Cd}$ presented a negative loading in this factor, which accounts for $7.22 \%$ of the total variance. Also, an intermediate positive loading was observed for $\mathrm{Zn}$. This positive relationship between $\mathrm{Sn}, \mathrm{As}$ and $\mathrm{Zn}$ and the specific surface could indicate that adsorption processes are controlling the incorporation of these elements to the sediments. On the other hand, the incorporation of Cd to sediments could be controlled by other processes not measured in this study and not related to the adsorption processes (e.g., sulfide associations; Ankley et al., 1991). Since the traditional formulas based on copper oxide as active component in anti-fouling paints were changed for the use of $\mathrm{Sn}$ and As compounds (Bryan and Langston, 1992; Azcue and Nriagu, 1994), this association could relate this factor to chemical sources, such as paints for boats used in nautical recreational activities. Due to the low variance explained in this factor, the interpretation of the associations described should be used with caution.

Factor 5: Geochemical matrix associated with Mn hydroxides

This factor, explaining only $7.26 \%$ of the total variance, showed a high loading only in $\mathrm{Mn}$ concentrations. Due to the fact that $\mathrm{Mn}$ is an element included in the geochemical matrix of marine sediments, it could associate this factor with variations in the geochemical matrix. Besides, the vertical Mn distributions reported by Aller (1980) showed that the surface sediments have lower values related to diagenetical processes. The maximum value is measured at depths between 5 and $10 \mathrm{~m}$, depending on the sedimentation rates in the area (Mangini et al., 1990). Based on this fact, these high levels of $\mathrm{Mn}$ in surface sediments included in this factor could be related to dredging processes which are periodically occurring at the entrance areas of the bay. Due to the lowest variance explained by this factor, the interpretation described may not be highly significant. asociación entre una variable original y un factor, y también tiene en cuenta las discontinuidades en las magnitudes de los pesos en las variables originales. Los valores negativos de estos pesos en los factores rotados son tan importantes como los valores positivos. Sin embargo, en este análisis, los pesos positivos son en general de mayor magnitud que los pesos negativos. En la tabla 4 se muestran los pesos siguiendo una rotación de varianza máxima (varimax) para los cinco factores. Cada factor es descrito de acuerdo al grupo dominante de variables.

Factor 1: Descarga de efluentes urbanos no tratados como fuente de contaminantes asociados con efectos adversos

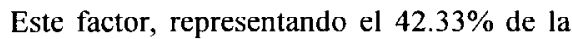
varianza total, tiene peso positivo en las concentraciones de sedimento de LAS, $\mathrm{Pb}, \mathrm{Ag}$ y OC y todas las respuestas de los ensayos de toxicidad. Los pesos de la concentración en sedimento de OC y de la respuesta en el ensayo de rotíferos $\left(\mathrm{TL}_{50}{ }^{-1}\right)$ mostraban valores menores comparados con el resto de las variables; estas variables tenían también pesos mayores que 0.5 en otros factores (OC, \#2 y \#3; $\mathrm{TL}_{50}{ }^{-1}$, \#3). La fuerte relación que existe entre las concentraciones en sedimento de LAS, Pb y Ag, típicamente asociadas con descargas de efluentes urbanos no tratadas (Bryan y Langston, 1992; González-Mazo et al., 1997), y los efectos biológicos medidos en todos los tests define este factor como descarga de efluentes urbanos no tratados como fuente de contaminantes asociados con efectos adversos.

Factor 2: Nivel basal de contaminación y matriz geoquímica del sedimento

Este factor, representando el $23.93 \%$ de la varianza total, tiene peso positivo en la concentración de los metales pesados $\mathrm{Ni}, \mathrm{V}, \mathrm{Co}, \mathrm{Fe}$, $\mathrm{Zn}$ y $\mathrm{Cu}$, la superficie específica y la concentración de OC total. Por otra parte, ninguna de las variables indicando efectos biológicos fue incluida en este factor. Basándose en esta asociación, este factor describe la composición de la matriz geoquímica de los sedimentos 
Based on this factor analysis, we propose that of the chemicals measured, the principal contaminants that are stressing the benthic ecosystems are: from factor $1, \mathrm{~Pb}, \mathrm{Ag}$, and LAS, measured in sediments from station $\mathrm{CB} 2$, and from factor 3, dissolved $\mathrm{Cr}$ and $\mathrm{Hg}$ in interstitial water from station CB5.

In order to confirm these factor descriptions and to establish the guidelines of sediment quality in the two littoral ecosystems studied here, we propose a representation of the estimated factor scores (and their mahalanobis distances, chi square) for each case (stations) to the centroid of all cases in the original data (fig. 4). We use the prevalence (factor scores) of factors for each of the cases studied to make the next three operative definitions based on the data obtained from the six acute toxicity tests. When the factor scores from factors 1 and 3, which show relationships between groups of chemicals and biological adverse effects, are zero or below with respect to all the cases, the maximum concentrations of toxic chemicals at any of those stations represent the maximum chemical concentrations not associated with adverse effects. These are considered to be concentrations below which biological effects are low or minimal and are here indicated as "no or minimal adverse biological effects". In contrast, to establish the minimal concentrations above which biological effects are always high, those minimal concentrations at stations where factor scores from factors 1 and 3 are higher than zero were selected and described here as "major adverse biological effects". Also, an intermediate range of chemical concentrations representing an "area of uncertainty", or a break point between the high and low concentrations, is shown.

The guidelines proposed for five different chemicals according to these three descriptions are shown in table 5. The rest of the chemicals measured in the different sediments selected in this study appear in concentrations below the biological effect detected and were not associated with any adverse effect. Determining sediment quality guidelines is a difficult task because of such factors as the partitioning of sediment contaminants between dissolved (i.e., interstitial waters) and particulate-bound estudiados representado por $O C$, la superficie específica y el metal $\mathrm{Fe}$ (hidróxidos de hierro), los cuales son tres parámetros importantes que controlan la incorporación de contaminantes al sedimento y que se encuentran también envueltos en la matriz de sedimentos de zonas costeras $y$ de estuario (Luoma, 1990). Tumbién las variables representando los metales pesados que están incluidas en este factor podrían estar relacionadas con aquellos niveles de base (nivel basal) publicados en estudios previos para el área estudiada (Gómez-Parra et al., 1984; Establier et al., 1985).

\section{Factor 3: Efectos adversos de los metales pesados $\mathrm{Hg}$ y $\mathrm{Cr}$ sobre Brachionus plicatilis}

Se observan pesos altos de los metales pesados $\mathrm{Hg}$ y $\mathrm{Cr}$ y de las respuestas biológicas del ensayo sobre $B$. plicatilis $\left(\mathrm{TL}_{50}{ }^{-1}\right)$ en este factor que representa el $14.24 \%$ de la varianza total. También, se observan pesos intermedios y positivos de Ag y As. Aunque los pesos de Ag y As estaban por encima de 0.5 , éstos no estaban asociados con efectos adversos, puesto que están mostrándose con pesos mayores en otros factores asociados con el efecto biológico $(\mathrm{Ag}$, factor 1) y sin efecto (As, factor 4). Estas correlaciones sugieren un efecto adverso de las concentraciones de metales disueltos $\mathrm{Hg}$ y $\mathrm{Cr}$ en el agua intersticial sobre B. plicatilis. El $\mathrm{Cr}$ es ampliamente empleado en el tratamiento de superficies metálicas, así como en otras actividades industriales (componentes de coches y aviones) cercanas a alguna de las áreas estudiadas. El $\mathrm{Hg}$ está también ampliamente utilizado en varios procesos industriales (Bryan $y$ Langston, 1992).

Factor 4: Fuentes de contaminación asociadas con actividades náuticas de recreo

Se observan pesos altos y positivos de Sn y As y de la superficie específica, mientras que el Cd presentaba un peso negativo en este factor, que representa el $7.22 \%$ de la varianza total. También, se observa un peso intermedio positivo de Zn. Esta relación positiva de $\mathrm{Sn}$, As y Zn y la superficie específica podría indicar que los procesos de adsorción están controlando la 
CB1

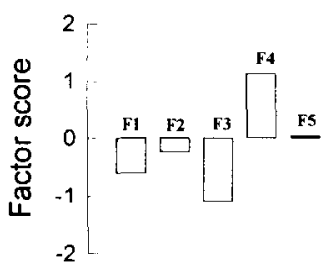

CB3

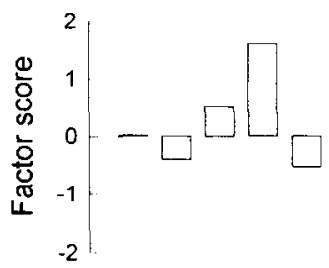

CB5

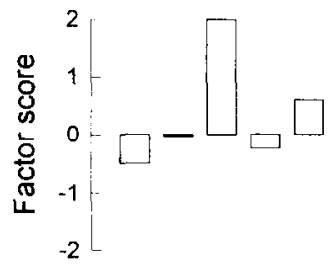

BR2
CB2

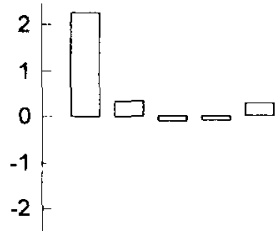

CB4

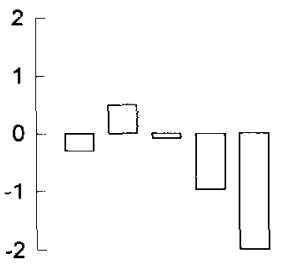

BR1

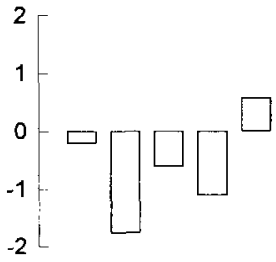

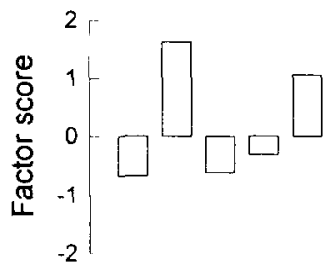

Figure 4. Estimated factor scores from each of the seven cases (five stations in the Bay of Cádiz: $\mathrm{CB} 1, \mathrm{CB} 2, \mathrm{CB} 3, \mathrm{CB} 4$ and $\mathrm{CB} 5$; and two stations at the salt marsh of the Barbate River: BR1 and BR2) to the centroid of all cases for the original data. The factor scores quantify the prevalence of every factor for each station and is used to calculate the sediment quality guidelines.

Figura 4. Contribuciones de los factores estimados para cada uno de los siete casos (cinco estaciones en la Bahía de Cádiz: CB1, CB2, CB3, CB4 y CB5; y dos estaciones en las marismas del río Barbate: BR1 y BR2) al centroide de todos los casos para los datos originales. La contribución de los factores cuantifica la influencia de cada factor para cada estación y es usado para calcular las guías de calidad del sedimento. 
Table 5. Sediment quality guidelines for $\mathrm{Cr}, \mathrm{Hg}, \mathrm{Pb}, \mathrm{Ag}$ and linear alkylbenzenesulphonate (LAS) proposed in this study. All concentrations were expressed as $\mathrm{mg} \mathrm{kg}^{-1}$ of dry sediment.

Tabla 5. Guias de calidad de sedimento para $\mathrm{Cr}, \mathrm{Hg}, \mathrm{Pb}, \mathrm{Ag}$ y el alquilbencenosulfonato lineal (LAS) propuestas en este estudio. Todas las concentraciones fueron expresadas como $\mathrm{mg} \mathrm{kg}^{-1}$ de sedimento seco.

\begin{tabular}{cccc}
\hline Contaminants & \multicolumn{3}{c}{ Guideline descriptions } \\
\cline { 2 - 4 } & $\begin{array}{c}\text { No or minimal adverse } \\
\text { biological effects }\end{array}$ & $\begin{array}{c}\text { Major adverse } \\
\text { biological effects }\end{array}$ & $\begin{array}{c}\text { Area of } \\
\text { uncertainty }\end{array}$ \\
\hline $\mathrm{Cr}$ & $<101.2$ & $>283.9$ & $101.2<\mathrm{c}<283.9$ \\
$\mathrm{Hg}$ & $<0.25$ & $>0.57$ & $0.25<\mathrm{c}<0.57$ \\
$\mathrm{~Pb}$ & $<66.8$ & $>84.64$ & $66.8<\mathrm{c}<84.64$ \\
$\mathrm{Ag}$ & $<0.78$ & $>1.34$ & $0.78<\mathrm{c}<1.34$ \\
$\mathrm{LAS}$ & $<2.6$ & $>62.1$ & $2.6<\mathrm{c}<62.1$ \\
\hline
\end{tabular}

fractions, which may render them more or less available to the organisms in the ecosystem. Because of these complexities, a comparative evaluation of broad-scale data sets encompassing complex interactions based on sediment toxicological data provides a promising alternative method for developing site-specific sediment quality guidelines. Furthermore, this method, deriving guideline concentrations, shown in tables 4 and 5 , and figure 4 , provides a conservative estimate based on interactions between complex chemical mixtures that may, individually or in combination, be responsible for the effects observed.

In the absence of sediment quality criteria specific for the two littoral ecosystems studied, the guidelines obtained here were compared to values derived from several proposed approaches (table 6). For this purpose, sediment management guidelines were used, proposed by the US Environmental Protection Agency, using site-specific sediment bioassays (Army Corps of Engineers, 1977); Ontario Ministry of the Environment, using the Screening Level Concentration (SLC) approach (Persaud et al., 1989), Washington State Marine Sediment Quality Standards derived for Puget Sound, using a combination of the Apparent Effects Threshold (AET) and Equilibrium Partitioning (EqP) methodologies (WADOE, 1991); and National Oceanic and Atmospheric Administration incorporación de estos elementos a los sedimentos. Por otro lado, la incorporación de $\mathrm{Cd}$ a los sedimentos podría ser controlada por otros procesos no medidos en este estudio y no relacionados con los procesos de adsorción (p.e., asociaciones con sulfuros; Ankley et al., 1991). Ya que las fórmulas tradicionales basadas en óxidos de cobre como componente activo en las pirturas anti-fouling fueron sustituidas por el uso de compuestos de Sn y As como componentes activos (Bryan y Langston, 1992; Azcue y Nriagu, 1994), esta asociación podría relacionar este factor con fuentes de contaminantes como pinturas para embarcaciones usadas en actividades náuticas de recreo. Debido a la baja varianza explicada en este factor, la interpretación de las asociaciones descritas debería ser usada con precaución.

Factor 5: Matriz geoquímica asociada con hidróxidos de Mn

Este factor, explicando sólo $5.73 \%$ de la varianza total, mostraba pesos altos solamente en las concentraciones de Mn. Debido al hecho de que el $\mathrm{Mn}$ es un elemento incluido en la matriz geoquimica de sedimentos marinos, esto podría asociar este factor con variaciones en la matriz geoquímica. Las distribuciones verticales de Mn reportadas por Aller (1980) mostraban que los sedimentos superficiales tienen 
Table 6. Summary of benchmark sediment quality guidelines ( $\mathrm{mg} \mathrm{kg}^{-1}$ dry weight) proposed to evaluate sediment quality guidelines obtained in the Gulf of Cádiz for $\mathrm{Pb}, \mathrm{Ag}, \mathrm{Cr}$ and $\mathrm{Hg}$ by different North American agencies and government bodies: (A) US Environmental Protection Agency (Army Corps of Engineers, 1977); (B) Ontario Ministry of Environment (Persaud et al., 1989); (C) National Oceanic and Atmospheric Administration (Long and Morgan, 1991); and (D) Washington State (WADOE, 1991). The surfactant LAS guidelines were not available. All concentrations are expressed as $\mathrm{mg} \mathrm{kg} \mathrm{kf}^{-1}$ of dry sediment.

Tabla 6. Resumen de los valores guías de calidad de sedimento ( $\mathrm{mg} \mathrm{kg}^{-1}$ peso seco) propuestos para evaluar las guias de calidad de sedimento obtenidas en el Golfo de Cádiz para $\mathrm{Pb}, \mathrm{Ag}, \mathrm{Cr}$ y $\mathrm{Hg}$ por diferentes agencias de América del Norte: (A) Environmental Protection Agency, Estados Unidos (Army Corps of Engineers, 1977); (B) Ontario Ministry of Environment (Persaud et al., 1989); (C) National Oceanic and Atmospheric Administration (Long y Morgan, 1991); y (D) Washington State (WADOE, 1991). Las guias asociadas con el tensioactivo no estaban disponibles. Todas las concentraciones están expresadas como $\mathrm{mg} \mathrm{kg}^{-1}$ de sedimento seco.

\begin{tabular}{|c|c|c|c|c|}
\hline \multicolumn{2}{|c|}{ Chemical } & \multicolumn{3}{|c|}{ Sediment quality guideline } \\
\hline & & Not polluted & Moderately polluted & Highly polluted \\
\hline \multirow[t]{4}{*}{$\mathrm{Pb}$} & (A) & $<40$ & $40-60$ & $>60$ \\
\hline & (B) & $<23$ & 31 & $>250$ \\
\hline & (C) & $<35$ & $35-110$ & $>110$ \\
\hline & (D) & ---* & $---*$ & $>450$ \\
\hline $\mathrm{Ag}$ & (C) & 1.0 & $1.0-2.2$ & $>2.2$ \\
\hline \multirow[t]{3}{*}{$\mathrm{Cr}$} & (A) & $<25$ & $25-75$ & $>75$ \\
\hline & (B) & $<22$ & $22-111$ & $>111$ \\
\hline & (C) & $<80.0$ & $80-145.0$ & $>145.0$ \\
\hline \multirow[t]{4}{*}{$\mathrm{Hg}$} & (A) & $<1.0$ & --- & $>1.0$ \\
\hline & (B) & $<0.12$ & $0.12-2.0$ & $>2.0$ \\
\hline & (C) & $<0.15$ & $0.15-1.3$ & $>1.3$ \\
\hline & (D) & ---* & $\ldots *$ & $>0.41$ \\
\hline
\end{tabular}

* Guideline not available.

(NOAA), from a compilation of the results of acute and chronic bioassays in several aquatic species (Long and Morgan, 1991). The similarities reported between data obtained in this study and those proposed by the various agencies suggest that the sediment quality data from the Gulf of Cádiz could converge on appropriate sediment quality guidelines, which are supported by substantial synoptic and available biological effect data and could, therefore, be widely applied.

This study presents the results of a chemical analysis and biological assessment of a few valores más bajos debidos a los procesos de diagénesis. El valor máximo se mide a profundidades entre 5 y $10 \mathrm{~m}$ dependiendo de las tasas de sedimentación del área (Mangini et al., 1990). Basándose en este hecho, estos niveles altos de $\mathrm{Mn}$ en los sedimentos superficiales incluidos en este factor podrían cstar rclacionados con procesos de dragado, los cuales se llevan a cabo periódicamente en las áreas de entrada de la bahía. Debido a que la varianza explicada por este factor es la más baja, la interpretación descrita podría no ser significativa. 
samples, seven tests and two controls, which are intended to provide a snapshot of sediment toxicity in two littoral ecosystems of the Gulf of Cádiz. Within the context of this study, we have attempted to provide a snapshot of the sediment quality, evaluating sediment, from which to derive a number of specific conclusions regarding the general water quality of the two ecosystems studied and compare the toxicity tests used. These conclusions are summarized below, based on the utilization of two samples as negative control or baseline condition and one as positive control or toxicity condition for the adverse effect:

(a) The battery designed was successful in measuring the toxicity effect of the sediment samples collected in the littoral area from the Gulf of Cádiz, using different sediment phases: whole sediment toxicity, sediment elutriates and interstitial water. Also, the chemicals measured were useful in determining different contamination sources and their relationships with toxicity effect.

(b) Two different sources of contamination and toxicity, and with different degree, were measured. One source was associated with an urban disposal point and characterized by high levels of $\mathrm{OC}, \mathrm{Pb}, \mathrm{Ag}$ and LAS. The second source was associated with an industrial disposal point related, principally, to high levels of the heavy metals $\mathrm{Cr}$ and $\mathrm{Hg}$. The other contamination sources were not associated with any toxicity effect measured with the toxicity test battery designed.

(c) In this study, the use of population declines of the rotifer Brachionus plicatilis is more sensitive than the other toxicity tests when toxicity associated with trace metal mixtures in field-collected sediments, especially related to high levels of $\mathrm{Cr}$ and $\mathrm{Hg}$ concentrations, is found. The results of the study presented here highlight the necessity and importance of the battery of tests approach for toxicity assessment. Each test responds in a unique way that emphasizes the intrinsic sensitivity of the test, the
Basándonos en este análisis de factores, proponemos que de aquellos contaminantes medidos en este estudio, los que son fuente de estrés en el ecosistema son: del factor $\mathrm{l}, \mathrm{Pb}, \mathrm{Ag}$ y LAS, medidos en los sedimentos de la estación $\mathrm{CB} 2$; y del factor $3, \mathrm{Cr}$ y $\mathrm{Hg}$ en el agua intersticial de la estación CB5.

Para confirmar estas descripciones de factores y para establecer las guías de calidad de sedimento en los dos ecosistemas litorales aquí estudiados, proponemos una representación del peso estimado (y sus distancias, chi cuadrado) para cada caso (estaciones) al centroide de todos los casos en los datos originales (fig. 4). Utilizamos la contribución (factor scores) de los factores en cada uno de los casos estudiados para hacer las tres siguientes definiciones operativas. Cuando la contribución de los factores 1 y/o 3, los cuales muestran relaciones entre grupos de contaminantes y efectos biológicos adversos, es cero o menor con respecto a todos los casos, la concentración máxima de contaminante tóxico en cualquiera de estas estaciones representa el máximo de la concentración de contaminantes no asociada con efectos adversos. Éstas son consideradas como concentraciones debajo de las cuales el efecto biológico es bajo o mínimo y se define aquí como "mínimo o ningún efecto biológico adverso". Por el contrario, para establecer la concentración mínima por encima de la cual siempre aparece el efecto biológico, aquellas concentraciones de contaminantes mínimas en las estaciones donde las contribuciones de los factores 1 y 3 son siempre mayores que cero fueron seleccionadas y definidas aquí como "mayor efecto biológico adverso". También se define un intervalo intermedio de concentraciones de contaminantes representando un "área de incertidumbre" o punto de rotura entre concentraciones altas y bajas.

Las guías propuestas para cinco contaminantes diferentes de acuerdo con estas tres descripciones se muestran en la tabla 5. El resto de los contaminantes medidos en los sedimentos seleccionados en este estudio aparecen en concentraciones por debajo de la cual el efecto biológico detectado no estuvo asociado con cualquier efecto adverso. La determinación de guías de calidad de sedimentos es difícil 
differences in species response, exposure routes, and the fate of the individual chemicals or classes of chemicals in the samples.

(d) Multivariate statistical method (factor analysis) provides a deeper insight into the structure of complex and diverse data and permits further conclusions. In addition, this multivariate tool reveals groupings of varying degrees of correlation between chemical concentrations in sediment and biological effects. The rclationships between $\mathrm{Pb}, \mathrm{Ag}$, linear alkylbenzenesulfonate (LAS), $\mathrm{Hg}$ and $\mathrm{Cr}$ concentrations in sediment and biological effects using different organisms are strong enough to permit the establishment of sediment quality guidelines. The comparison with other data offers the opportunity to establish which of these chemicals are associated with the adverse effect measured. In this sense, and associated with the two different sources of contamination identified above, $\mathrm{Pb}, \mathrm{Ag}, \mathrm{LAS}$, $\mathrm{Hg}$ and $\mathrm{Cr}$ concentrations in sediment were the most important chemicals associated with the adverse effect and we propose the guidelines shown in table 5 for them.

\section{ACKNOWLEDGEMENTS}

The authors thank Carmen Piñuela for critically reading the manuscript and three anonymous referees. Thanks are also due to Lina and C.UPIMAR S.A. for fish larvae collection. This work was supported as part of project AMB94-0291, financed by a grant from the Spanish Science and Technology Interministerial Commission (CICYT).

\section{REFERENCES}

Aller, R.C. (1980). Diagenetic processes near the sediment-water interface of Long Island Sound. II. Fe and Mn. Geophysics, 22: 351-415.

Ankley, G.T. and Schubauer-Berigan, M.K. (1994). Comparison of techniques for the isolation of sediment pore water for toxicity testing. Arch. Environ. Contam. Toxicol., 27: 507-512.

Ankley, G.T., Phipps, G.L., Leonard, E.N., Benoit, D.A., Mattson, V.R., Koisan, P.A., Cotter, A.M., debido a factores como la distribución de los contaminantes entre las fracciones disueltas (p.e., agua intersticial) y las asociadas con el material sólido, las cuales podrían estar más o menos biodisponibles para los organismos en el ecosistema. Debido a estas complejidades, la evaluación comparativa de series de datos que incluyan interacciones complejas basadas en datos de toxicidad de sedimentos provee un prometedor método alternativo para el desarrollo de guias de calidad de sedimentos en áreas específicas. $\Lambda$ demás, este método, mostrado en las tablas 4 y 5 y la figura 4 , para derivar guías de concentraciones, ofrece una estimación conservativa basada en las interacciones entre mezclas complejas de contaminantes que podrian, individualmente $o$ en combinación, ser responsables de los efectos observados.

En ausencia de criterios especificos de calidad de sedimentos para los dos ecosistemas estudiados, las guías obtenidas aquí fueron comparadas con valores derivados por diversos métodos propuestos (tabla 6). Con este propósito, se utilizaron las guías de calidad de sedimento propuestas por la agencia norteamericana de conservación del medioambiente (USEPA), usando bioensayos específicos de sedimento (Army Corps of Engineers, 1977); el ministerio del medioambiente de Ontario, utilizando el método del nivel de concentración de screening (SLC) (Persaud et al., 1989); los estándares de calidad de sedimento marino del estado de Washington obtenidos para Puget Sound, utilizando una combinación de los métodos de los efectos aparentes de umbral (AET) y el método de la distribución en el equilibrio (EqP) (WADOE, 1991); y la oficina para la administración nacional del océano y la atmósfera norteamericana (NOAA), utilizando una recopilación de resultados obtenidos de ensayos crónicos y agudos de toxicidad sobre diferentes especies acuáticas (Long y Morgan, 1991). La similitud apreciada entre los datos obtenidos en este estudio y entre los propuestos por las mencionadas agencias sugiere que los datos de calidad de sedimento para el Golfo de Cádiz podrían converger en apropiadas guías de calidad de sedimento, las cuales están apoyadas substancialmente por efectos biológicos 
Dierkes, J.R. and Mahony, J.D. (1991). Acidvolatile sulfide as a factor mediating cadmium and nickel bioavailability in contaminated sediments. Environ. Toxicol. Chem., 10: 1299-1307.

APHA (1985). Standard Methods for the Examination of Water and Wastewater. 15th ed. American Public Health Association, Washington, DC, $1260 \mathrm{pp}$.

Arjonilla, M., Forja, J.M. and Gómez-Parra, A. (1994). Sediment analysis does not provide a good measure of heavy metal bioavailability to Cerastoderma glaucum (Mollusca: Bivalvia) in confined coastal ecosystems. Bull. Environ. Contam. Toxicol., 52: 810-817.

Army Corps of Fngineers (1977). Implementation Manual for Section 103 of Public Law 92-532: Marine Protection, Research and Sanctuaries Act of 1972. July 1977. US Army Corps of Engineers, Environmental Effects Laboratory, Waterways Experiment Section, Vicksburg, MS.

ASTM (1991). Standard guide for collection, storage, characterization and manipulation of sediments for toxicological testing. Publ. E 1391-90. American Society for Testing and Matcrials, Philadelphia.

ASTM (1993) Standard guide for conducting 10-day static sediment toxicity tests with marine and estuarine amphipods. 1367-92. American Society for Testing and Materials, Publ. E. Philadelphia, $26 \mathrm{pp}$.

Azcue, J.M. and Nriagu, IO. (1994). Arsenic: Historical perspectives. In: J.O. Nriagu (ed.), Arsenic in the Environment. Part I: Cycling and Characterization. John Wiley, New York, pp. 1-15.

Bryan, G.W. and Langston, W.J. (1992). Bioavailability, accumulation and effects of heavy metals in sediments with special reference to United Kingdom estuaries: a review. Environ. Pollut., 76: 89-131.

Bulger, J.A., Hayden, B.P., Monaco, M.E., Nelson, D.M. and McCormick-Ray, M.G. (1993). Biologically-based estuarine salinity zones derived from a multivariate analysis. Estuaries, 16(2): 311-322.

Bulich, A.A., Greene, M.W. and Isenberg, D.L. (1981). The reliability of the bacterial luminescence assay for the determination of toxicity of pure compounds and complex effluents. In: D.R. Branson and K.L. Dickson (eds.), Proc. 4th Annual Symposium on Aquatic Toxicology, ASTM STP 737, pp. 339-347. disponibles y sinópticos, y podrían, de esta forma, ser ampliamente utilizadas.

Este estudio presenta el resultado de un análisis químico y una valoración biológica de unas pocas muestras, siete tests y dos controles, los cuales intentan proveer una primera valoración de la toxicidad de sedimentos en los dos ecosistemas litorales estudiados en el Golfo de Cádiz. En el contexto de este estudio, hemos intentado proveer una primera valoración de la calidad del sedimento, derivando un número de conclusiones específicas en cuanto a la calidad general del agua de los dos ecosistemas litorales y comparando los tests de toxicidad utilizados. Estas conclusiones están resumidas a continuación, basándose en la utilización de dos muestras de control negativa o condición basal y un control positivo o condición tóxica para el efecto adverso:

(a) La batería diseñada fue un éxito midiendo los efectos tóxicos de las muestras de sedimento del área litoral del Golfo de Cádiz, incluyendo diferentes fases de sedimento: sedimento bruto, extractos de sedimento y agua intersticial. También, los contaminantes seleccionados fueron de utilidad para determinar las diferentes fuentes de contaminación y su relación con el efecto tóxico.

(b) Se midieron dos fuentes distintas de contaminación y toxicidad, y con diferente grado. Una de ellas fue asociada con un punto de descarga de efluentes urbanos caracterizado por niveles altos de $\mathrm{OC}, \mathrm{Pb}, \mathrm{Ag}$ y LAS. La segunda fuente fue asociada con un punto de descarga industrial relacionada, principalmente, con niveles altos de los metales pesados $\mathrm{Cr}$ y $\mathrm{Hg}$. Las otras fuentes de contaminación no estuvieron asociadas con lus efectos tóxicos medidos en la batería de ensayos de toxicidad diseñada.

(c) En este estudio, se demuestra que el uso del decaimiento de poblaciones del rotífero Brachionus plicatilis es más sensible que los otros tests de toxicidad cuando la toxicidad está asociada con mezclas de metales traza en sedimentos obtenidos en el campo, 
Chapman, P.M. (1988). Marine sediment toxicity tests. In: J.J. Lichtenberg, F.A. Winter, C.I. Weber and L. Fradkin (eds.), Chemical and Biological Characterization of Sludges, Sediments, Dredge Spoils and Drilling Fluids. STP 976. American Society for Testing and Materials, Philadelphia, PA, pp. 391-402.

Comrey, A.L. (1973). A First Course in Factor Analysis. Academic Press, New York, 198 pp.

DelValls, T.A. (1994). Aplicación de un método integrado para la medida de la calidad ambientai en ecosistemas litorales del Golfo de Cádiz. Tesis doctoral, Universidad de Cádiz, Cádiz, España, 389 pp.

DelValls, T.A. and Chapman, P.M. Site-specific sediment quality values in the Gulf of Cádiz (Spain) and in San Francisco Bay (USA) using the sediment quality triad and the multivariate analysis. Ciencias Marinas (in press).

DelValls, T.A., Blasco, J., Rubio, J.A., Forja, J.M. and Gómez-Parra, A. (1994). Seasonality of sediment toxicity in two littoral ecosystems of Cádiz Gulf (SW Spain). Proc. 6th Environmental Contamination Conference, Delphi, Greece. 10-12 October 1994, pp. 395-398.

DelValls, T.A., Lubián, L.M., González-del Valle, M. and Forja, J.M. (1996). Evaluating decline parameters of rotifer Brachionus plicatilis populations as an interstitial water toxicity bioassay. Hydrobiologia, 341: 159-167.

DelValls, T.A., Lubián, L.M., Forja, J.M. and Gómez-Parra, A. (1997). Comparative ecotoxicity of interstitial waters using Microtox and the rotifer Brachionus plicatilis. Environ. Toxicol. Chem., 16(11): 2323-2333.

DelValls, T.A., Blasco, J., González-Mazo, E., Forja, J.M. and Gómez-Parra, A. Determining contamination sources in marine sediments using multivariate analysis. TrAck-Trends in Analytical Chemistry (in press).

Establier, R., Gómez-Parra, A. and Blasco, J. (1985). Superficial accumulation of heavy metals in nearshore sediments, an objective index of environmental pollution. Bull. Environ. Contam. Toxicol, 35: 348-353.

El Rayis, O.A. (1985). Re-assessment of the titration method for determination of organic carbon in recent sediments. Rapp. Comm. int. Mer. Medit., 29: $45-47$.

Frane, J., Jennrich, R. and Sampson, P. (1985). Factor analysis. In: W.J. Dixon (ed.), BMDP Statistical Software. Univ. California Press, Berkeley, pp. 480-500. especialmente relacionados con niveles altos de $\mathrm{Cr}$ y $\mathrm{Hg}$. Los resultados de este estudio recalcan la necesidad y la importancia del uso de baterías de tests para la valoración de la toxicidad. Cada test responde de una manera única que enfatiza la sensibilidad intrínseca del test, las diferencias de respuestas con las especies, las rutas de exposición y el comportamiento de los contaminantes individuales o de las clases de contaminantes en las muestras.

(d) El método estadístico multivariante (análisis de factores) provee un profundo aprovechamiento de la estructura de datos diversos $y$ complejos y permite mayores conclusiones. Además, esta herramienta multivariante revela, agrupando los grados de variación, las correlaciones entre las concentraciones de contaminantes en sedimentos y los efectos biológicos. Las relaciones de las concentraciones de $\mathrm{Pb}, \mathrm{Ag}, \mathrm{LAS}, \mathrm{Hg}$ y $\mathrm{Cr}$ en sedimento con los efectos biológicos utilizando diferentes organismos son suficientemente fuertes como para permitir el establecimiento de guías de calidad de sedimento. La comparación con otros datos ofrece la oportunidad para establecer cuáles de estos contaminantes están asociados con el efecto adverso medido. En este sentido, y asociado con las dos fuentes de contaminación identificadas, las concentraciones en sedimento de $\mathrm{Pb}, \mathrm{Ag}$, LAS, Hg y Cr fueron las más importantes de los contaminantes asociados con el efecto adverso y nosotros proponemos para ellos las guías mostradas en la labla 5 .

\section{AGRADECIMIENTOS}

Los autores agradecen a Carmen Piñuela su lectura crítica de una versión previa del manuscrito, asi como a tres revisores anónimos. También agradecen a Lina y CUPIMAR S.A. la ayuda suministrada durante el ensayo de larvas de dorada. El trabajo descrito fue realizado como parte del proyecto AMB94-0291, financiado por la Comisión Interministerial de Ciencia y Tecnología de España (CICYT).

Traducido al español por los autores. 
Gaudette, H.E., Flight, W.R., Torner, L. and Folger, D.W. (1974). An inexpensive titration method for the determination of organic carbon in recent sediments. J. Sedim. Petrol., 44: 249-253.

Giesy, J.P. and Hoke, R.A. (1989). Freshwater sediment quality criteria: toxicity bioassessment. In: R. Baudo, J.P. Giesy and H. Muntau (eds.), Sediments: Chemistry and Toxicity of In-place Pollutants. Lewis Publishers, Ann Arbor, MI, pp. 265-348.

Gómez-Parra, A., Establier, R. and Escolar, D. (1984). Heavy metals in recent sediments from Bay of Cádiz, Spain. Mar. Pollut. Bull., 15(8): 307-310.

Gonzálcz-Mazo, E., Quiroga, J.M., Salcs, D. and Gómez-Parra, A. (1997). Levels of linear alkylbenzenesulfonate (LAS) in waters and sediments of the coastal ecosystems of the Gulf of Cádiz. Toxicol. Environ. Chem., 59: 77-87.

Long, E.R. and Morgan, L.G. (1991). The potential for biological effects of sediment-sorbed contaminants tested in the national status and trends program. US NOAA Technical Memorandum NOS/OMA 52, 2nd printing, 228 pp.

Loring, D.H. and Rantala, R.T.T. (1992). Methods for the geochemical analyses of marine sediments and suspended particulate matter. EarthScience Rev., 32: 235-283.

Luoma, S.N. (1990). Processes affecting metal concentrations in estuarine and coastal marine sediments. In: R.W. Fürness and P.S. Rainbow (eds.), Heavy Metals in the Environment. CRC Press, Boca Raton, Florida, pp. 51-66.

Luoma, S.N. and Ho, K.T. (1992). The appropriate uses of marine and estuarine sediment bioassays In: P. Calow (ed.), The Handbook of Ecotoxicology. Vol. 1. Blackwell Scientific Publications, Cambridge, MA, pp. 193-226.

Mangini, A., Eisenhauer, A. and Walter, P. (1990). The relevance of manganese in the ocean for the climatic cycles in the quaternary. Mathematischnaturwissenschaftliche Klase, 4: 1-31.

McGreer, E.R. (1979). Sublethal effects of heavy metal contaminated sediments on the bivalve Macoma balthica (L.). Mar. Pollut. Bull., 10: 259-262.

Persaud, D., Jaagumagi, R. and Hayton, A. (1989). Development of Provincial Sediment Quality Guidelines. Ontario Ministry of Environment, Water Resources Branch, Aquatic Biology Section, Toronto, Ontario, Canada, $19 \mathrm{pp}$

Polo, A. (1991). Crecimiento y alimentación durante el desarrollo larvario de la dorada, Sparus aurata, L., en cultivo. Tesis doctoral, Universidad de Cádiz, España, 179 pp.

Washington State Department of Ecology (WADOE) (1991). Sediment Management Standards, $\mathrm{Ch}$. 173-204 WAC. Sediment Management Unit, Olympia, Washington, April.

Zitko, V. (1994). Principal component analysis in the evaluation of environmental data. Mar. Pollut. Bull., 28: 718-722. 